Revista de
Economild
Contemporâned

\title{
POLÍTICA FISCAL EM PERSPECTIVA: O CICLO DE 16 ANOS (1999-2014)
}

\author{
Sérgio Wulff Gobetti ${ }^{a}$ \\ Rodrigo Octávio Orair
}

\begin{abstract}
aTécnico de Planejamento e Pesquisa do IPEA (Diretoria de Estudos e Políticas Macroeconômicas), cedido ao Ministério da Fazenda.

b'Técnico de Planejamento e Pesquisa do IPEA (Diretoria de Estudos e Políticas Regionais, Urbanas e Ambientais) e pesquisador associado ao International Policy Centre for Inclusive Growth (IPC-IG).
\end{abstract}

Artigo recebido em 04/10/2015 e aceito em 09/11/2015.

RESUMO: Este artigo oferece uma contribuição para o debate sobre as mudanças no regime fiscal brasileiro, caracterizando melhor o ciclo de contração e expansão da política fiscal entre 1999 e 2014. Em primeiro lugar, analisa estatísticas inéditas do resultado primário acima da linha que incorporam a esfera regional de governo. Isto permite compreender melhor a recente fase expansionista da política fiscal brasileira (2010-2014), identificando não só seus determinantes em termos de receitas e despesas, mas também o componente derivado dos governos estaduais e municipais. Adicionalmente, emprega diversos indicadores para caracterizar melhor esta fase expansionista em comparação com períodos anteriores. Por fim, analisa a sustentabilidade da trajetória da despesa pública em diferentes cenários.

PALAVRAS-CHAVE: expansão fiscal; resultado estrutural; impulso fiscal.

CLASSIFICAÇÃO JEL: E62; E65; H62. 


\section{FISCAL POLICY IN PERSPECTIVE: THE 16-YEAR CYCLE (1999-2014)}

ABSTRACT: This paper contributes to the debate over fiscal regime changes in Brazil, better characterizing the cycle of contraction and expansion of fiscal policy between 1999 and 2014.Firstly, the paper presents an analysis based on detailed statistics about primary budget balance that incorporate regional level of government in order to provide a better understanding of the recent expansionary fiscal policy in Brazil (2010-2014). It identifies not only the main determinants in terms of revenues and expenditures but also those related to local and state governments. Additionally, several indicators were used to better characterize that fiscal expansion compared to previous periods and, finally, the paper analyzes the sustainability of public spending trajectory under different scenarios.

KEYWORDS: fiscal expansion; structural balance; fiscal impulse. 


\section{INTRODUÇÃO*}

As dificuldades do governo em promover o ajuste fiscal que, de acordo com a hipótese da "contração expansionista"1, resgataria a credibilidade dos agentes privados nos rumos da política econômica e cimentaria o caminho para a retomada do crescimento, têm mostrado que os obstáculos de natureza conjuntural e estrutural para controlar os gastos públicos são maiores do que muitos economistas acreditavam, e que o caminho quase inexorável para elevar no curto prazo o resultado primário passa, mais uma vez, pelo tradicional padrão de ajuste que combina corte de investimentos com aumento da carga tributária.

Essa evidência reforça a necessidade de não só estudar mais profundamente o que ocorreu com as contas públicas no período recente, mas fazer uma comparação com outras fases do ciclo da política fiscal iniciado a partir da adoção do regime de metas de superavit primário, em 1999. Isso será feito a partir de estimativas do resultado primário das administrações públicas (União, estados e municípios) decomposto entre receitas e despesas, o que nos permite ter uma visão mais ampla e qualificada da evolução das finanças públicas.

A inclusão da esfera regional de governo é uma contribuição inédita deste texto, que procura preencher uma lacuna na literatura ${ }^{2}$. Ao mesmo tempo, serão utilizadas medidas alternativas, como resultados ajustados ao ciclo econômico e taxas de crescimento real das despesas, com o intuito de avaliar melhor a intensidade da expansão fiscal recente (2011-2014), bem como suas características e vetores determinantes em comparação com os três períodos anteriores de governo (1999-2002, 2003-2006 e 2007-2010).

O resultado dessa análise mostra que, nos últimos 16 anos, embora tenhamos praticamente sete anos de uma fase contracionista da política fiscal (1999-2005), seguidos de nove anos da fase expansionista (2006-2014), a média de crescimento real da despesa primária no agregado pouco variou. Isso evidencia não só uma elevada rigidez da des-

\footnotetext{
A série do PIB do IBGE foi recentemente revisada para os anos recentes, posteriormente ao aceite e revisão do artigo, de modo que não foi possível considerá-la no cálculo dos indicadores.

1 Hipótese originalmente formulada por Giavazzi e Pagano (1990), ao estudarem alguns episódios de consolidação fiscal que, segundo os autores, teriam elevado o nível de atividade por canais não keynesianos, fundamentalmente pelas expectativas.

2 Como bem afirma Giambiagi (2008, p. 559-560): "No que se refere às contas de estados e municípios, não se pode apresentar evidências acerca da evolução desagregada dos indicadores de receita e despesa como foi feito para o governo central, por inexistirem dados compilados dessa forma acima da linha para os governos subnacionais. Os indicadores parciais desse tipo que existem, apresentados no site do Tesouro Nacional, não têm séries muito antigas, sofrem do problema do aumento da cobertura com o passar dos anos e são disponibilizados com grande defasagem. O que se pode comentar é o que ocorreu com o resultado fiscal abaixo da linha apurado pelo Banco Central [...], e com alguns indicadores específicos de receita".
} 
pesa, mas certa inércia, associada principalmente aos gastos sociais em geral e, mais precisamente, aos benefícios sociais previdenciários e assistenciais ${ }^{3}$.

Por outro lado, argumenta-se que a discricionariedade da política fiscal se reflete principalmente nas taxas de crescimento das despesas de custeio, investimentos e subsídios (além de desonerações), e foi possível identificar uma mudança na composição da política fiscal durante a fase expansionista: inflexão entre um período cujo espaço fiscal foi canalizado predominantemente para investimentos (2006-2010) e um período de maior expansão das despesas de custeio, subsídios e desonerações (2011-2014).

O estudo sugere ainda que o impacto da desaceleração econômica sobre os indicadores fiscais mais recentes é maior do que o mostrado pelas análises puramente baseadas nos indicadores estruturais, ajustados ao ciclo econômico e com exclusão das receitas não recorrentes ${ }^{4}$, primeiramente porque a variável-chave para esta análise, o PIB tendencial, medido por filtro estatístico, está em queda acentuada, e, em segundo lugar, porque há evidências de uma relação endógena entre as receitas tributárias e o nível de atividade econômica, que gera uma assimetria das elasticidades das receitas em relação ao ciclo econômico. Essa assimetria não vem sendo considerada pelas abordagens convencionais de resultado estrutural. Tais problemas tendem a ocasionar uma subestimativa do impulso fiscal pelo lado da receita e uma superestimativa pelo lado da despesa.

Por fim, com o intuito de contribuir com uma agenda de reforma de médio prazo, será aprofundada a análise sobre o que tem ocorrido com as despesas com benefícios sociais. Indicamos que sua tendência é continuar crescendo acima do PIB, tanto mais quanto menor for o crescimento da economia, apesar da regra que vincula a correção do salário mínimo - isto é, o piso dos benefícios previdenciários e assistenciais - ao crescimento da própria economia.

O artigo é constituído de seis seções, incluindo esta introdução e as considerações finais. Na segunda seção analisamos a evolução do resultado primário de setor público abaixo e acima da linha; na terceira seção utilizamos indicadores de resultado estrutural ajustado ao ciclo econômico; e na quarta e na quinta seções avaliamos especificamente a trajetória de mais longo prazo das despesas do governo central.

3 Exclusive benefícios previdenciários dos servidores públicos inativos, que, neste texto, aparecerão embutidos na rubrica de gasto de pessoal.

4 Tais procedimentos consistem basicamente em projetar, a partir de estimativas das elasticidades das receitas, qual teria sido a arrecadação e o resultado fiscal caso o produto não se desviasse de sua trajetória tendencial. 


\section{EVOLUÇÃO DO RESULTADO PRIMÁRIO DO SETOR PÚBLICO}

As estatísticas fiscais do setor público mostram que, embora a tendência de queda do resultado primário se manifeste há mais tempo, como parte de uma fase expansionista da política fiscal ${ }^{5}$, foi nos três últimos anos que a situação se agravou substancialmente. $\mathrm{O}$ resultado primário abaixo da linha, segundo o Banco Central do Brasil (BCB), caiu de um superavit de 2,94\% do PIB, em 2011, para um deficit de $0,59 \%$ do PIB, em 2014 (ver Tabela 1), o que representa uma queda de 3,53 pontos percentuais (p.p.) do PIB em três anos ${ }^{6}$.

$\mathrm{Na}$ esfera central de governo, a queda no resultado primário atingiu 2,50 p.p. do PIB; na esfera regional, foram 0,89 p.p. do PIB; e, entre as empresas estatais, já excluídas a Petrobras e a Eletrobras, a queda foi de 0,14 p.p. do PIB. Uma parcela dessa deterioração pode ser atribuída ao ciclo eleitoral, já que estamos comparando o primeiro com o último ano dos mandatos na esfera federal e estadual. Ainda assim, a constatação de que houve piora considerável dos indicadores fiscais não se altera se a comparação for feita para um período um pouco mais longo (desde 2008 ou 2009) ou a partir da análise dos indicadores tradicionais de resultado estrutural ${ }^{7}$.

A fim de analisar em maior profundidade os fatores que explicam a deterioração do resultado fiscal, é preciso, em primeiro lugar, olhar para as estatísticas acima da linha, ou seja, aquelas que apresentam o resultado fiscal das administrações públicas a partir do detalhamento de suas receitas e despesas. Esse tipo de estatística é mensalmente divulgado pela Secretaria do Tesouro Nacional (STN) para a esfera central de governo. Contudo, ainda está em processo de construção para a esfera regional, demandando um trabalho meticuloso de harmonização conceitual e depuração dos balanços fiscais das 27 Unidades da Federação (UFs) e dos mais de 5,5 mil municípios brasileiros.

Utilizamos neste estudo estimativas preliminares desse trabalho, com base em procedimentos estatísticos e econométricos para lidar com problemas de cobertura e de intempestividade das informações de estados e municípios. Desse modo, mesclando os dados do resultado do governo central e os dados preliminares do resultado dos governos regionais ${ }^{8}$, foi possível construir um quadro de consolidação do resul-

5 Indicadores de resultado fiscal ajustado ao ciclo econômico e com exclusão de receitas não recorrentes (Schettini et al., 2011; Brasil, 2014) mostram que a inflexão da fase contracionista da política fiscal para a fase expansionista se deu entre 2004 e 2005, embora as estatísticas convencionais apontem o pico de superavit primário em 2008.

6 O resultado abaixo da linha representa o resultado apurado a partir da variação do endividamento e dos juros, enquanto o resultado acima da linha é apurado pela diferença entre receitas e despesas.

7 Esses indicadores serão discutidos na próxima seção.

8 As despesas dos estados foram apuradas com base em estimativas pelo critério de caixa, enquanto as despesas dos municípios foram estimadas com base nos empenhos, exceto 2014, quando os valores de pagamen- 
tado primário acima da linha das administrações públicas, ou governo geral, para o período de 2009 a 2014, o qual está sintetizado na Tabela 2.

Tabela 1 - Resultado primário do setor público consolidado, 1996-2014 (em \% do PIB)

\begin{tabular}{lcccc}
\hline Ano & Governo central & Governos regionais & Empresas estatais & Total \\
\hline 1996 & 0,37 & $-0,49$ & 0,03 & $-0,09$ \\
1997 & $-0,06$ & $-0,67$ & $-0,13$ & $-0,87$ \\
1998 & 0,59 & $-0,17$ & $-0,41$ & 0,01 \\
1999 & 2,08 & 0,19 & 0,57 & 2,85 \\
2000 & 1,57 & 0,50 & 1,10 & 3,17 \\
2001 & 1,67 & 0,80 & 0,71 & 3,18 \\
2002 & 2,14 & 0,71 & 0,33 & 3,19 \\
2003 & 2,25 & 0,80 & 0,18 & 3,23 \\
2004 & 2,67 & 0,89 & 1,12 & 3,69 \\
2005 & 2,57 & 0,98 & 0,19 & 3,74 \\
2006 & 2,13 & 0,82 & 0,20 & 3,15 \\
2007 & 2,19 & $-0,05$ & 3,24 \\
2008 & 2,75 & 1,10 & 0,05 & 3,79 \\
\hline 2009 & 1,28 & 0,98 & 0,04 & 1,95 \\
2010 & 1,21 & 0,63 & 0,06 & 1,80 \\
2011 & 2,13 & 0,53 & 0,06 & 2,94 \\
2012 & 1,56 & 0,75 & $-0,06$ & 1,96 \\
2013 & 1,46 & $-0,01$ & 1,77 \\
2014 & $-0,37$ & 0,46 & $-0,08$ & $-0,59$ \\
\hline
\end{tabular}

Notas: (1) Exclui a Petrobras e a Eletrobras a partir de 2002. (2) Exclui efeitos do Fundo Soberano do Brasil e da capitalização da Petrobras.

Fonte: BCB/Séries Temporais.

Antes de entrar propriamente na análise desse quadro, convém fazer alguns esclarecimentos metodológicos sobre sua estruturação.

A série do PIB do IBGE foi recentemente revisada para os anos recentes, posteriormente ao aceite e revisão deste artigo, de modo que não foi possível considerá-la no cálculo dos indicadores.

Dados do governo central foram ajustados conforme proposto em Gobetti (2015), excluindo-se das receitas e das despesas o efeito de operações intraorçamentárias, como as decorrentes da compensação pela desoneração da folha de pagamentos, as transferências do Tesouro ao BCB e a operação de cessão onerosa ou capitalização da Petrobras.

Dados do governo central oriundos do Tesouro Nacional foram complementados com informações do Sistema Integrado de Administração Financeira do Governo Federal (SIAFI), com a identificação dos valores gastos nos programas Bolsa Família e Minha Casa Minha Vida (MCMV), em investimentos e inversões financeiras, além 
das transferências correntes e de capital para estados e municípios que não fazem parte do agregado transferências legais e constitucionais.

Dados de estados e municípios também foram ajustados de modo a apresentarem as receitas e as despesas sem o efeito das contribuições patronais para os regimes próprios de previdência, tendo em vista mudanças na sua forma de contabilização e seu caráter intraorçamentário.

As despesas foram classificadas e reunidas em seis grupos: $i$ ) pessoal (incluindo parcela do BCB); ii) benefícios sociais (previdenciários e assistenciais, exclusive de servidores públicos e inclusive Bolsa Família); iii) subsídios (incluindo gastos do programa MCMV e auxílio à Conta de Desenvolvimento Energético); iv) custeio; v) investimento; e vi) outros (incluindo inversões financeiras e gastos do BCB, no caso do governo central) ${ }^{9}$.

Receitas e despesas do governo geral foram consolidadas eliminando-se as transferências intergovernamentais para evitar dupla contagem.

A discrepância estatística referida na última linha da Tabela 2 corresponde à diferença entre os resultados acima e abaixo da linha. Não é possível identificar qual apuração concentra mais os erros de mensuração. É mais provável que os erros estejam presentes em ambas, mas a apuração abaixo da linha é considerada mais confiável, por se basear nas informações dos fluxos de endividamento com o setor financeiro, enquanto a acima da linha calcula o resultado a partir das informações declaratórias de milhares de unidades de governo.

Tabela 2 - Resultado primário do governo geral, 2009-2014 (em \% do PIB)

\begin{tabular}{l|lrrrrrrr}
\hline \multirow{5}{*}{ União } & Discriminação & $\mathbf{2 0 0 9}$ & $\mathbf{2 0 1 0}$ & $\mathbf{2 0 1 1}$ & $\mathbf{2 0 1 2}$ & $\mathbf{2 0 1 3}$ & $\mathbf{2 0 1 4}$ & $\mathbf{2 0 0 9 - 2 0 1 4}$ \\
\cline { 2 - 8 } & Receita Primária & 22,18 & 21,71 & 22,59 & 22,45 & 22,68 & 21,80 & $-0,38$ \\
& Receita tributária & 13,70 & 13,69 & 14,30 & 13,96 & 14,16 & 13,56 & $-0,14$ \\
& Receita previdenciária & 5,47 & 5,45 & 5,62 & 5,81 & 5,78 & 5,79 & 0,32 \\
& Demais & 3,01 & 2,57 & 2,67 & 2,68 & 2,75 & 2,45 & $-0,56$ \\
& Transferências legais & 3,84 & 3,62 & 3,94 & 3,85 & 3,68 & 3,81 & $-0,03$ \\
& Receita líquida & 18,34 & 18,09 & 18,65 & 18,60 & 19,00 & 17,99 & $-0,35$ \\
& Despesa total & 17,16 & 16,88 & 16,51 & 16,99 & 17,51 & 18,30 & 1,15 \\
& Pessoal & 4,61 & 4,33 & 4,14 & 3,99 & 3,97 & 4,02 & $-0,59$ \\
& Benefícios sociais & 8,49 & 8,24 & 8,16 & 8,61 & 8,89 & 9,29 & 0,80 \\
& Subsídios & 0,18 & 0,23 & 0,41 & 0,46 & 0,62 & 0,65 & 0,46 \\
& Custeio & 2,78 & 2,84 & 2,73 & 2,87 & 3,00 & 3,22 & 0,44 \\
& d/q transferências & 1,36 & 1,37 & 1,29 & 1,36 & 1,24 & 1,26 & $-0,10$ \\
& Investimentos & 0,97 & 1,15 & 0,96 & 0,99 & 0,92 & 1,04 & 0,07 \\
& d/q transferências & 0,36 & 0,38 & 0,31 & 0,42 & 0,28 & 0,30 & $-0,06$ \\
& Inversões financeiras & 0,14 & 0,08 & 0,10 & 0,07 & 0,10 & 0,09 & $-0,05$ \\
& Resultado Primário & 1,18 & 1,21 & 2,14 & 1,61 & 1,49 & $-0,31$ & $-1,50$ \\
\hline
\end{tabular}

(continua)

9 O gasto de custeio do governo central não corresponde exatamente ao informado pela STN, porque não inclui alguns benefícios sociais e subsídios, e porque foi estimado por resíduo, deduzindo-se do total da despesa primária os demais componentes desta, alguns dos quais obtidos pelo SIAFI. 
Tabela 2 - Resultado primário do governo geral, 2009-2014 (em \% do PIB) (continuação)

\begin{tabular}{|c|c|c|c|c|c|c|c|c|}
\hline \multirow{15}{*}{ Estados } & Discriminação & 2009 & 2010 & 2011 & 2012 & 2013 & 2014 & 2009-2014 \\
\hline & Receita Primária & 11,65 & 11,48 & 11,34 & 11,46 & 11,63 & 11,61 & $-0,05$ \\
\hline & Receita tributária & 8,59 & 8,62 & 8,51 & 8,72 & 8,99 & 8,96 & 0,37 \\
\hline & Receita de transferência & 2,23 & 2,10 & 2,08 & 2,00 & 1,88 & 1,94 & $-0,30$ \\
\hline & Demais & 0,84 & 0,76 & 0,75 & 0,74 & 0,76 & 0,71 & $-0,12$ \\
\hline & Transferências totais & 2,24 & 2,27 & 2,16 & 2,27 & 2,23 & 2,30 & 0,06 \\
\hline & Receita líquida & 9,41 & 9,22 & 9,19 & 9,19 & 9,39 & 9,31 & $-0,11$ \\
\hline & Despesa total & 8,75 & 8,65 & 8,25 & 8,61 & 9,08 & 9,50 & 0,75 \\
\hline & Pessoal & 5,43 & 5,29 & 5,32 & 5,54 & 5,70 & 5,94 & 0,50 \\
\hline & Benefícios sociais & 0,03 & 0,03 & 0,03 & 0,04 & 0,04 & 0,04 & 0,02 \\
\hline & Subsídios & 0,00 & 0,00 & 0,00 & 0,00 & 0,01 & 0,01 & 0,00 \\
\hline & Custeio & 1,91 & 1,82 & 1,75 & 1,87 & 1,96 & 1,98 & 0,07 \\
\hline & Investimentos & 0,92 & 1,05 & 0,71 & 0,70 & 0,91 & 1,05 & 0,13 \\
\hline & Outras & 0,46 & 0,46 & 0,44 & 0,45 & 0,45 & 0,48 & 0,02 \\
\hline & Resultado Primário & 0,66 & 0,57 & 0,93 & 0,58 & 0,31 & $-0,19$ & $-0,86$ \\
\hline \multirow{14}{*}{ Municípios } & Receita Primária & 7,78 & 7,75 & 7,85 & 8,24 & 8,05 & 8,33 & 0,55 \\
\hline & Receita tributária & 1,92 & 1,93 & 1,99 & 2,10 & 2,17 & 2,30 & 0,38 \\
\hline & Receita de transferência & 5,42 & 5,34 & 5,41 & 5,67 & 5,48 & 5,64 & 0,22 \\
\hline & Demais & 0,44 & 0,48 & 0,45 & 0,47 & 0,41 & 0,39 & $-0,05$ \\
\hline & Transferências totais & 0,04 & 0,05 & 0,04 & 0,04 & 0,06 & 0,05 & 0,01 \\
\hline & Receita líquida & 7,75 & 7,70 & 7,82 & 8,21 & 7,99 & 8,28 & 0,54 \\
\hline & Despesa total & 7,57 & 7,55 & 7,69 & 8,13 & 7,87 & 8,20 & 0,63 \\
\hline & Pessoal & 3,77 & 3,63 & 3,67 & 3,94 & 4,05 & 4,25 & 0,48 \\
\hline & Benefícios sociais & 0,03 & 0,03 & 0,03 & 0,03 & 0,03 & 0,03 & 0,01 \\
\hline & Subsídios & 0,00 & 0,00 & 0,00 & 0,00 & 0,00 & 0,00 & 0,00 \\
\hline & Custeio & 2,73 & 2,64 & 2,71 & 2,73 & 2,66 & 2,74 & 0,01 \\
\hline & Investimentos & 0,77 & 0,90 & 0,92 & 1,01 & 0,73 & 0,79 & 0,02 \\
\hline & Outras & 0,27 & 0,35 & 0,36 & 0,42 & 0,38 & 0,39 & 0,12 \\
\hline & Resultado Primário & 0,17 & 0,15 & 0,12 & 0,08 & 0,12 & 0,08 & $-0,09$ \\
\hline \multirow{11}{*}{ Governo Geral } & Receita Primária & 33,79 & 33,25 & 34,06 & 34,22 & 34,87 & 34,02 & 0,23 \\
\hline & d/q não recorrentes & 0,71 & 0,07 & 0,38 & 0,27 & 0,68 & 0,50 & $-0,20$ \\
\hline & Despesa total & 31,77 & 31,33 & 30,86 & 31,95 & 32,94 & 34,44 & 2,68 \\
\hline & Pessoal & 13,81 & 13,26 & 13,14 & 13,47 & 13,73 & 14,21 & 0,39 \\
\hline & Benefícios sociais & 8,54 & 8,30 & 8,22 & 8,68 & 8,97 & 9,36 & 0,82 \\
\hline & Subsídios & 0,19 & 0,24 & 0,41 & 0,47 & 0,64 & 0,66 & 0,47 \\
\hline & Custeio & 6,06 & 5,93 & 5,90 & 6,10 & 6,38 & 6,68 & 0,62 \\
\hline & Investimentos & 2,30 & 2,71 & 2,27 & 2,28 & 2,29 & 2,58 & 0,28 \\
\hline & Outras & 0,87 & 0,89 & 0,91 & 0,95 & 0,94 & 0,96 & 0,09 \\
\hline & Resultado Primário & 2,02 & 1,92 & 3,19 & 2,27 & 1,93 & $-0,42$ & $-2,44$ \\
\hline & Discrepância estatística & $-0,11$ & $-0,18$ & $-0,31$ & $-0,25$ & $-0,15$ & $-0,09$ & 0,03 \\
\hline
\end{tabular}

Fonte: Elaboração própria. 
Em que pese a discrepância estatística variar devido a fatores desconhecidos, ela é muito próxima em 2009 e 2014, de modo que a comparação entre os resultados acima da linha desses dois anos oferece um bom panorama sobre os fatores determinantes do comportamento do resultado primário. Além disso, ambos os anos - o primeiro e o último da série - apresentam situações similares em relação ao ciclo econômico, no sentido de que os PIBs estão abaixo do seu nível tendencial ${ }^{10}$.

Feitas essas considerações iniciais, podemos observar pela Tabela 2 que a queda do resultado primário nos últimos anos se deve, no agregado da administração pública (exclusive estatais), fundamentalmente ao crescimento das despesas, uma vez que a receita permaneceu relativamente estabilizada, crescendo entre 2009 e 2013 e caindo em 2014 para praticamente o mesmo patamar de 2009.

Aparentemente as desonerações promovidas pelo governo federal nos últimos anos foram compensadas pelo efeito da formalização, principalmente na arrecadação sobre a folha de pagamentos (inclusive contribuições sociais), e por medidas em sentido contrário, ou por melhorias na arrecadação da esfera regional, como se vê pelo comportamento das receitas tributárias de estados e municípios, que cresceram respectivamente 0,37 p.p. e 0,38 p.p. do PIB entre 2009 e 2014 . Tal padrão de comportamento das receitas primárias é consistente com a evolução de outro indicador, a carga tributária, que também cresceu entre 2009 e 2014, segundo estimativas de Orair (2015), expressas no Gráfico $1^{11}$. O que se vê, por ambos os indicadores, de receita primária ou carga tributária, é que - apesar das oscilações cíclicas e das desonerações - prevalece uma tendência de certa estabilidade em proporção do PIB.

Quanto às despesas, a incorporação dos dados de estados e municípios enriquece a análise por mostrar que a expansão do gasto não se restringe à esfera central. Enquanto o governo federal aumenta o gasto principalmente por três vias (benefícios sociais, subsídios e custeio), os governos regionais estão ampliando consideravelmente as despesas com pessoal ativo e inativo, na direção oposta ao que ocorre na União.

\footnotetext{
${ }^{10}$ Estimativas com base em filtro Hodrick-Prescott (HP) que serão relatadas posteriormente.

${ }^{11}$ É importante notar que o conceito de carga tributária difere do de receita primária. Por um lado, a carga exclui receitas de natureza não tributária, como as receitas de concessões, compensações financeiras (royalties, por exemplo), dividendos e multas/juros. Por outro lado, a carga tributária inclui parcelas que não compõem a receita primária do governo geral, como as contribuições ao Fundo de Garantia do Tempo de Serviço (FGTS) e ao Sistema S.
} 


\section{Gráfico 1 - Carga tributária, 2002-2014 (em \% do PIB)}

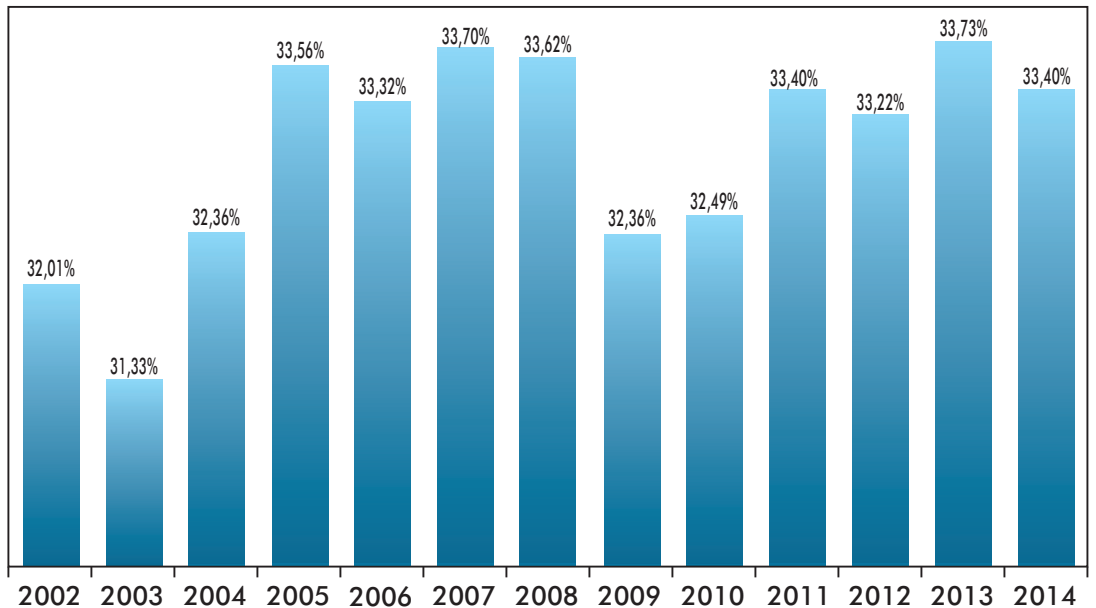

Fonte: Orair (2015).

Entre 2009 e 2014, a despesa com pessoal cresceu 0,98 p.p. do PIB na esfera regional e caiu 0,59 p.p. na esfera federal, resultando em aumento líquido de 0,39 p.p. do PIB no consolidado da administração pública. Os benefícios sociais se ampliaram 0,82 p.p. do PIB (sendo 0,80 p.p. na União); os subsídios, 0,47 p.p. do PIB (0,46 p.p. na União); e o custeio, 0,62 p.p. do PIB, quase exclusivamente por influência da União.

Os investimentos, por sua vez, apresentaram - excluindo-se os anos de eleições presidenciais e de governadores estaduais, 2010 e 2014 - estabilidade entre 2,27\% e $2,30 \%$ do PIB. Isso distingue o período recente do início da fase expansionista da política fiscal, quando a criação de espaço fiscal foi predominantemente canalizada para essa finalidade ${ }^{12}$.

Nos últimos quatro anos, ao contrário, o espaço fiscal decorrente da redução do resultado primário foi canalizado principalmente para despesas correntes e, na esfera federal, também para desonerações tributárias. Contudo, os dois principais vetores que explicam o aumento da despesa corrente - benefícios sociais, na esfera federal, e despesas de pessoal, na esfera regional - não surgiram recentemente, estando presentes há mais tempo na evolução das contas públicas e sendo responsáveis por sua elevada rigidez.

12 De acordo com Afonso e Gobetti (2015), mais de 40\% da redução do superavit primário estrutural entre 2005 e 2010 foram canalizados para investimentos da administração pública, sem contar a expansão dos investimentos das empresas estatais. 
No caso dos benefícios sociais, a expansão do gasto decorre tanto da quantidade de beneficiários quanto do seu preço, predominantemente vinculado ao salário mínimo, como veremos em mais detalhes na quinta seção. As despesas de pessoal de estados e municípios crescem por distintos fatores endógenos e exógenos às autoridades fiscais regionais. As evidências sugerem que essa expansão se deu de modo generalizado por quase todas as UFs, a taxas nominais que variam entre 52\% e 115\%, e independentemente de viés político-partidário ${ }^{13}$.

Um exemplo de fator estrutural exógeno são as pressões demográficas (envelhecimento populacional) sobre as despesas previdenciárias. Mas uma das hipóteses principais, a ser investigada nos estudos subsequentes a este trabalho, é que essa expansão está vinculada aos reajustes do salário mínimo, sobretudo nos governos das regiões menos desenvolvidas, com elevada proporção de servidores recebendo o piso salarial. Também está vinculada à expansão dos programas federais e dos fundos multigovernamentais das áreas sociais básicas (saúde, educação e assistência social), nos quais a execução das políticas públicas se dá de maneira descentralizada pelos estados e municípios. Estudos como o de Gobetti e Orair (2010) identificam uma tendência de crescimento das transferências intergovernamentais destinadas às áreas sociais básicas - muitas das quais com vinculações diretas às despesas de pessoal -, em relação às demais transferências.

De maneira mais geral, está em curso um movimento de expansão do gasto social, que ocorre principalmente na forma de aumento das despesas de pessoal, na esfera regional, ou dos benefícios sociais, na esfera federal. Esse movimento reflete as pressões em favor de transferências redistributivas e da consolidação de um Estado de bem-estar social, com ampliação do acesso a serviços sociais básicos pela população. Essas pressões respondem em grande medida pela elevada rigidez e pelo caráter inercial das despesas, as quais remontam pelo menos à renovação do contrato social após a Constituição Federal de 1988.

\section{OUTROS INDICADORES DE ANÁLISE DOS RESULTADOS FISCAIS}

A análise empreendida na seção anterior já delineia os principais determinantes por trás da deterioração recente dos resultados fiscais. Entretanto, uma forma mais recomendada pela literatura para avaliar o que ocorre com as contas públicas em termos estrutu-

\footnotetext{
13 Tomando-se o exemplo dos maiores estados, o aumento nominal da despesa com pessoal foi de $63 \%$ no Ceará; 69\% em São Paulo; 74\% em Pernambuco; 86\% na Bahia; 87\% no Rio Grande do Sul; $91 \%$ no Rio de Janeiro; $92 \%$ em Minas Gerais; $98 \%$ no Paraná; e 99\% em Santa Catarina.
} 
rais é a aplicação de procedimentos de ajustamento ao ciclo, que implicam estimar quais seriam os resultados fiscais caso a economia não se desviasse de seu nível tendencial. No Brasil, nos anos recentes, vários estudos têm buscado adaptar de modo mais sofisticado as metodologias internacionais - como as da Organização de Cooperação e Desenvolvimento Econômico (OCDE) e do Fundo Monetário Internacional (FMI) - ao caso brasileiro. Entre eles, destacamos Schettini et al. (2011), Oreng (2011) e Brasil (2014).

Não é o escopo deste texto aprofundar o debate sobre essas metodologias, mas apenas aplicá-las ao resultado primário acima da linha das administrações públicas, de modo a compará-lo com as estatísticas convencionais. Para isso, nosso referencial geral, inclusive pela maior atualidade das estimativas, será o trabalho desenvolvido pela Secretaria de Política Econômica do Ministério da Fazenda (Brasil, 2014), com algumas adaptações, como a expressão dos resultados em proporção do PIB tendencial (e não do PIB efetivo), o que é mais adequado para avaliar o resultado decomposto em receitas e despesas.

Partindo das elasticidades dos principais grupos de receita tributária sujeitos ao ajuste, estimadas em Brasil (2014) ${ }^{14}$, e das estimativas atualizadas dos componentes cíclico e tendencial do PIB, extraídos pelo filtro Hodrick Prescott (HP), chegamos ao resultado ajustado ao ciclo, cuja memória de cálculo está apresentada no apêndice. Em seguida, são obtidas as estimativas do resultado estrutural das administrações públicas, apresentadas na Tabela 3, que correspondem ao resultado ajustado ao ciclo menos as receitas não recorrentes e mais a discrepância estatística obtida por resíduo entre os resultados acima e abaixo da linha.

Como teste de consistência, comparamos o componente cíclico estimado neste trabalho com os resultados de Brasil (2014). Considerando-se que estamos utilizando a nova série do PIB (efetivo e tendencial), bem como expressando os resultados em proporção do PIB tendencial em vez do efetivo, as diferenças não são expressivas, e mostraram divergências de no máximo 0,22 p.p. do PIB em 2009 e 0,17 p.p. do PIB em $2010^{15}$.

Os resultados indicam que o resultado primário das administrações públicas (exclusive estatais), em termos estruturais, caiu 2,67 p.p. do PIB tendencial entre 2009 e

\footnotetext{
14 São utilizadas aproximações das elasticidades estimadas pela SPE (conforme detalhado no Apêndice), inclusive porque nossos cálculos foram feitos na base anual e não trimestral, como em Brasil (2014).

${ }^{15}$ Os componentes cíclicos estimados de 2009 e 2010 são menores que os de Brasil (2014) não só pelo denominador ser um PIB maior em valores nominais, mas por não ajustarmos as receitas do petróleo, que apresentaram queda cíclica nesse período. Além disso, por simplicidade, não ajustamos ao ciclo, como faz a SPE, as receitas com impostos sobre importação e com impostos sobre ganhos de capital. Em compensação, realizamos um ajuste baseado em modelo determinístico relativamente complexo para distribuir o efeito cíclico dos tributos partilhados entre mais de uma esfera da federação e cujo detalhamento se encontra no Apêndice.
} 
2014, enquanto pelas estatísticas convencionais a queda foi de 2,42 p.p. (incluindo discrepância estatística). Ou seja, a magnitude da expansão não se altera muito com a adoção de procedimentos de ajuste ao ciclo econômico e expurgo de receitas não recorrentes, porque, como já salientado, a economia se encontrava aproximadamente na mesma posição do ciclo nos dois anos ${ }^{16}$.

Contudo, a mensuração do impulso fiscal ano a ano se altera devido às flutuações do ciclo e aos diferentes níveis de receitas não recorrentes. Mais importante que isso, a decomposição dos impulsos entre receitas e despesas fica mais acurada quando explicitamos os resultados ajustados ao ciclo, líquidos de receitas não recorrentes, e em proporção do PIB tendencial. Por exemplo, entre 2013 e 2014, o impulso expansionista da administração pública derivado da variação do resultado estrutural foi estimado em 1,41 p.p. do PIB tendencial, sendo 0,85 p.p. decorrente da expansão das despesas. No diagnóstico convencional, temos uma queda do resultado primário de 2,3 p.p. do $\mathrm{PIB}$, sendo 1,5 p.p. decorrente de aumento da despesa ${ }^{17}$.

Tabela 3 - Resultado primário estrutural do governo geral, 2009-2014 (em \% do PIB tendencial)

\begin{tabular}{l|lrrrrrrr}
\hline & Discriminação & $\mathbf{2 0 0 9}$ & $\mathbf{2 0 1 0}$ & $\mathbf{2 0 1 1}$ & $\mathbf{2 0 1 2}$ & $\mathbf{2 0 1 3}$ & $\mathbf{2 0 1 4}$ & $\mathbf{2 0 0 9 - 2 0 1 4}$ \\
\hline \multirow{5}{*}{ Governo Geral } & Receita Primária* & 33,85 & 33,23 & 34,03 & 34,22 & 34,86 & 34,03 & 0,19 \\
& d/q não recorrentes & 0,69 & 0,07 & 0,38 & 0,27 & 0,69 & 0,50 & $-0,19$ \\
& Despesa total & 30,92 & 31,60 & 31,29 & 32,05 & 33,14 & 33,99 & 3,08 \\
& Pessoal & 13,44 & 13,38 & 13,32 & 13,51 & 13,81 & 14,02 & 0,57 \\
& Benefícios sociais & 8,31 & 8,37 & 8,34 & 8,71 & 9,02 & 9,24 & 0,93 \\
& Subsídios & 0,18 & 0,24 & 0,42 & 0,47 & 0,64 & 0,65 & 0,47 \\
& Custeio & 5,89 & 5,98 & 5,99 & 6,12 & 6,42 & 6,59 & 0,70 \\
& Investimentos & 2,24 & 2,74 & 2,30 & 2,29 & 2,30 & 2,54 & 0,31 \\
& Outras & 0,85 & 0,90 & 0,93 & 0,95 & 0,94 & 0,95 & 0,11 \\
& Resultado Primário* & 2,93 & 1,63 & 2,73 & 2,17 & 1,72 & 0,04 & $-2,89$ \\
& Discrepância estatística & $-0,11$ & $-0,19$ & $-0,32$ & $-0,25$ & $-0,16$ & $-0,09$ & 0,02 \\
& Resultado estrutural ${ }^{*}$ & 2,13 & 1,38 & 2,03 & 1,65 & 0,87 & $-0,54$ & $-2,67$ \\
\hline
\end{tabular}

${ }^{16}$ Esta similaridade de posição no ciclo tende a se alterar se reestimarmos o PIB tendencial por meio de filtro com a introdução de dados ou estimativas atualizadas para o comportamento do PIB em 2015 e 2016, que terão como efeito o deslocamento da tendência para baixo, indicando que em 2014 o PIB teria estado acima do nível tendencial mesmo crescendo apenas $0,2 \%$.

${ }_{17}$ Se, por outro lado, adotássemos a metodologia da SPE e expressássemos os resultados estruturais em proporção do PIB efetivo e não tendencial, chegaríamos à conclusão de que o impulso expansionista de 2014 teria sido de 1,42 p.p., praticamente idêntico ao que estimamos, mas decomposto em impulso de 1,51 p.p. pelo lado da despesa e de apenas 0,16 p.p. pelo lado da receita, subestimando muito o efeito das desonerações. 
Tabela 3 - Resultado primário estrutural do governo geral, 2009-2014 (em \% do PIB tendencial) (continuação)

\begin{tabular}{|c|c|c|c|c|c|c|c|c|}
\hline & Discriminação & 2009 & 2010 & 2011 & 2012 & 2013 & 2014 & 2009-2014 \\
\hline \multirow{16}{*}{ União } & Receita primária* & 22,29 & 21,67 & 22,53 & 22,44 & 22,66 & 21,84 & $-0,45$ \\
\hline & Receita tributária* & 13,95 & 13,61 & 14,17 & 13,93 & 14,10 & 13,67 & $-0,28$ \\
\hline & Receita previdenciária* & 5,41 & 5,47 & 5,65 & 5,82 & 5,79 & 5,76 & 0,35 \\
\hline & Demais & 2,93 & 2,59 & 2,71 & 2,69 & 2,77 & 2,42 & $-0,51$ \\
\hline & Transferências legais* & 3,87 & 3,61 & 3,93 & 3,85 & 3,68 & 3,82 & $-0,05$ \\
\hline & Receita líquida* & 18,42 & 18,06 & 18,61 & 18,59 & 18,99 & 18,02 & $-0,40$ \\
\hline & Despesa total & 16,70 & 17,03 & 16,74 & 17,05 & 17,62 & 18,06 & 1,36 \\
\hline & Pessoal & 4,49 & 4,37 & 4,20 & 4,00 & 4,00 & 3,97 & $-0,52$ \\
\hline & Benefícios sociais & 8,26 & 8,32 & 8,28 & 8,64 & 8,95 & 9,17 & 0,90 \\
\hline & Subsídios & 0,18 & 0,23 & 0,41 & 0,46 & 0,63 & 0,64 & 0,46 \\
\hline & Custeio & 2,70 & 2,87 & 2,77 & 2,87 & 3,02 & 3,18 & 0,48 \\
\hline & d/q transferências & 1,32 & 1,38 & 1,30 & 1,36 & 1,25 & 1,25 & $-0,08$ \\
\hline & Investimentos & 0,94 & 1,16 & 0,97 & 1,00 & 0,92 & 1,02 & 0,08 \\
\hline & d/q transferências & 0,35 & 0,39 & 0,31 & 0,42 & 0,28 & 0,30 & $-0,05$ \\
\hline & Inversões financeiras & 0,13 & 0,08 & 0,11 & 0,07 & 0,10 & 0,09 & $-0,04$ \\
\hline & Resultado Primário & 1,72 & 1,04 & 1,86 & 1,55 & 1,37 & $-0,04$ & $-1,76$ \\
\hline \multirow{14}{*}{ Estados } & Receita Primária* & 11,65 & 11,49 & 11,35 & 11,46 & 11,63 & 11,60 & $-0,04$ \\
\hline & Receita tributária* & 8,60 & 8,62 & 8,51 & 8,72 & 8,99 & 8,96 & 0,36 \\
\hline & Receita de transferência & 2,24 & 2,10 & 2,08 & 2,00 & 1,88 & 1,94 & $-0,30$ \\
\hline & Demais & 0,81 & 0,77 & 0,76 & 0,74 & 0,77 & 0,70 & $-0,11$ \\
\hline & Transferências totais* & 2,26 & 2,26 & 2,15 & 2,27 & 2,23 & 2,31 & 0,05 \\
\hline & Receita líquida* & 9,39 & 9,22 & 9,20 & 9,20 & 9,40 & 9,30 & $-0,09$ \\
\hline & Despesa total & 8,52 & 8,72 & 8,37 & 8,64 & 9,14 & 9,38 & 0,86 \\
\hline & Pessoal & 5,29 & 5,34 & 5,40 & 5,56 & 5,74 & 5,86 & 0,57 \\
\hline & Benefícios sociais & 0,03 & 0,03 & 0,03 & 0,04 & 0,04 & 0,04 & 0,02 \\
\hline & Subsídios & 0,00 & 0,00 & 0,00 & 0,00 & 0,01 & 0,01 & 0,00 \\
\hline & Custeio & 1,85 & 1,83 & 1,77 & 1,87 & 1,98 & 1,95 & 0,10 \\
\hline & Investimentos & 0,90 & 1,06 & 0,72 & 0,71 & 0,92 & 1,04 & 0,14 \\
\hline & Outras & 0,45 & 0,46 & 0,45 & 0,45 & 0,45 & 0,48 & 0,03 \\
\hline & Resultado primário & 0,87 & 0,50 & 0,83 & 0,56 & 0,26 & $-0,08$ & $-0,95$ \\
\hline \multirow{14}{*}{ Municípios } & Receita primária* & 7,74 & 7,76 & 7,88 & 8,25 & 8,06 & 8,30 & 0,56 \\
\hline & Receita tributária* & 1,89 & 1,94 & 2,01 & 2,11 & 2,17 & 2,28 & 0,39 \\
\hline & Receita de ransferências* & 5,43 & 5,34 & 5,41 & 5,67 & 5,48 & 5,64 & 0,21 \\
\hline & Demais & 0,43 & 0,48 & 0,45 & 0,47 & 0,41 & 0,39 & $-0,04$ \\
\hline & Transferências totais & 0,04 & 0,05 & 0,04 & 0,04 & 0,06 & 0,05 & 0,01 \\
\hline & Receita líquida* & 7,70 & 7,71 & 7,84 & 8,21 & 8,00 & 8,26 & 0,55 \\
\hline & Despesa total & 7,37 & 7,62 & 7,80 & 8,16 & 7,92 & 8,10 & 0,72 \\
\hline & Pessoal & 3,67 & 3,66 & 3,72 & 3,95 & 4,08 & 4,19 & 0,52 \\
\hline & Benefícios sociais & 0,03 & 0,03 & 0,03 & 0,03 & 0,03 & 0,03 & 0,01 \\
\hline & Subsídios & 0,00 & 0,00 & 0,00 & 0,00 & 0,00 & 0,00 & 0,00 \\
\hline & Custeio & 2,66 & 2,67 & 2,74 & 2,74 & 2,68 & 2,71 & 0,05 \\
\hline & Investimentos & 0,74 & 0,91 & 0,93 & 1,01 & 0,74 & 0,78 & 0,03 \\
\hline & Outras & 0,27 & 0,35 & 0,37 & 0,43 & 0,39 & 0,39 & 0,12 \\
\hline & Resultado Primário & 0,33 & 0,10 & 0,04 & 0,06 & 0,09 & 0,16 & $-0,17$ \\
\hline
\end{tabular}

Nota: (*) Variáveis submetidas ao ajuste ao ciclo econômico.

Fonte: Elaboração própria. 
A seguir são apresentados dois gráficos ilustrativos dessa abordagem. No primeiro (Gráfico 2), compara-se o impulso fiscal estimado pela variação do resultado estrutural com aquele derivado da simples variação do resultado convencional, sem ajuste ao ciclo e sem exclusão de receitas não recorrentes. No segundo (Gráfico 3), decompõe-se o impulso fiscal entre receitas e despesas, além do componente não explicado derivado das discrepâncias estatísticas entre os resultados acima e abaixo da linha. Os impulsos expansionistas são expressos com sinal positivo, e os impulsos contracionistas, com sinal negativo.

O Gráfico 3 sugere que pelo lado da receita tivemos três anos seguidos de contração, entre 2011 e 2013, enquanto pelo lado das despesas só tivemos uma contração em 2011, concentrada exclusivamente sobre os investimentos. Entre 2012 e 2014, observou-se a recuperação parcial dos investimentos e uma expansão das despesas puxada por todas as categorias de despesas correntes: pessoal (concentrada em estados e municípios), benefícios sociais, subsídios e custeio (principalmente na esfera federal e, em menor grau, nos estados).

Gráfico 2 - Impulso fiscal, 2010-2014 (em \% do PIB)

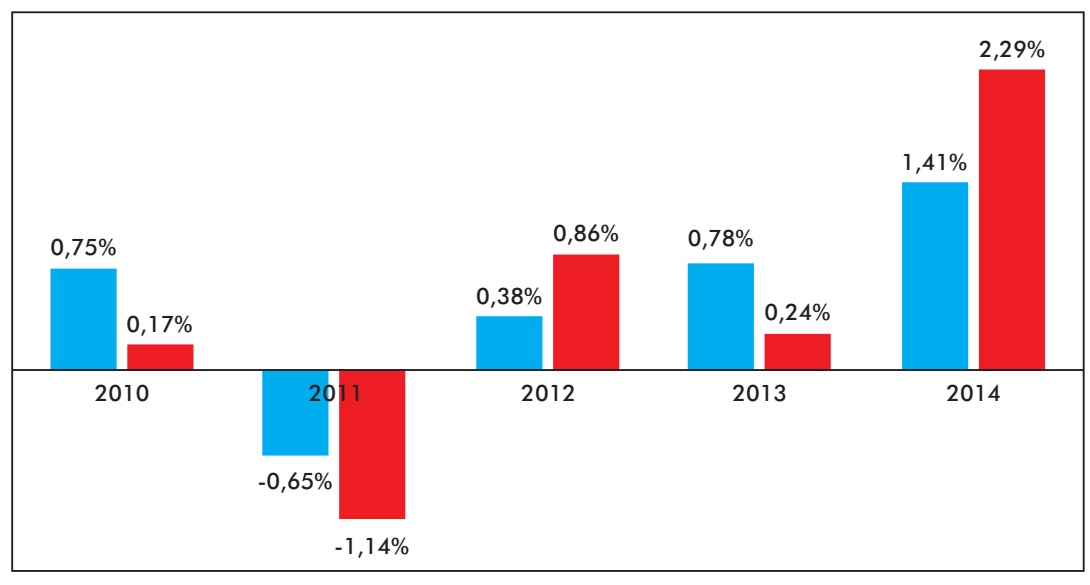

Estrutura

Convencional

Fonte: Elaboração própria. 


\section{Gráfico 3 - Impulso fiscal anual, por fator determinante, 2010-2014 (em \% do PIB)}

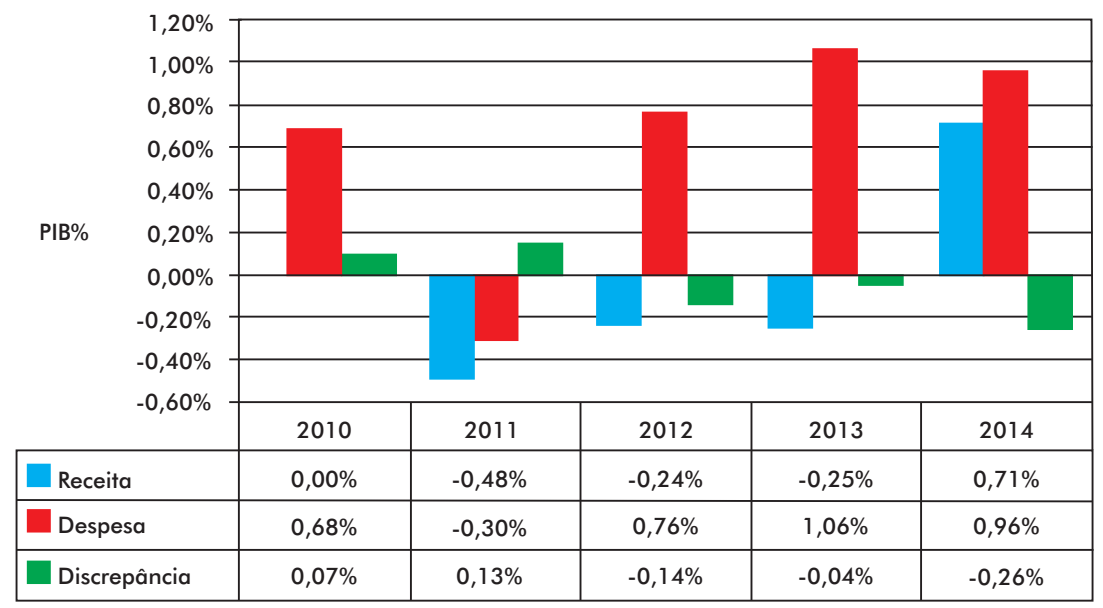

Fonte: Elaboração própria.

Apesar da evidente superioridade do indicador estrutural sobre os indicadores fiscais convencionais para a análise qualitativa da política fiscal, existem alguns limites que merecem menção e que emergem da análise empírica que acabamos de realizar. Por exemplo, os dados indicam que a política fiscal pelo lado das receitas teria sido contracionista ou, na melhor das hipóteses, neutra entre 2009 e 2014, quando sabemos que a política tributária do período foi caracterizada pelo crescente volume de desonerações tributárias. Se nos atermos à receita previdenciária, vamos observar que ela crescia em proporção do PIB até 2012, quando entrou em vigor a desoneração da folha de pagamento, momento a partir do qual a arrecadação passa a se estabilizar.

Como mostra Orair (2015), as desonerações tributárias desse período mais recente não conduziram à queda da carga tributária devido a fatores autônomos não captados pelo indicador do produto, relacionados principalmente ao processo simultâneo de expansão da massa salarial com formalização do mercado de trabalho. Esse mesmo estudo verificou a presença de descasamentos nas relações entre determinadas bases tributáveis e o PIB, a exemplo dos lucros das grandes empresas e ganhos de capital, que são mais voláteis e suscetíveis aos ciclos do mercado financeiro.

Assim, existem fatores estruturais autônomos em relação ao nível de atividade econômica que impulsionaram as receitas tributárias e que mascaram o caráter expansionista da política tributária. Além disso, as elasticidades de curto prazo das receitas em relação ao produto tendem a se reduzir nas fases de desaceleração econômica, devido aos descasamentos das bases tributáveis. Essa assimetria cíclica das elasticidades não vem sendo considerada pelas abordagens convencionais de resultado estrutural. 
Esse problema tem sido agravado pelo efeito da desaceleração econômica sobre a inclinação da curva do PIB tendencial estimada por filtro estatístico. A redução nas estimativas do PIB tendencial nos anos recentes tende a magnificar o efeito expansionista estimado pela variação das receitas ajustadas ao ciclo. Consequentemente, o impulso fiscal derivado da variação da receita em termos estruturais deixa de ser um bom termômetro da discricionariedade da política fiscal, sendo necessário buscar métodos complementares. Retomaremos este ponto nas considerações finais.

Em contrapartida, pelo lado das despesas, processa-se o efeito contrário. A desaceleração econômica tende a elevar o indicador de gasto em proporção do PIB tendencial (e efetivo), independentemente do ritmo de crescimento das despesas. Mesmo que haja certa vinculação entre as taxas de crescimento real das despesas públicas e da economia - seja por vinculações de uma parcela das despesas (efeito sobre o salário mínimo ou gasto mínimo em saúde, por exemplo), seja porque são um componente do próprio PIB e influenciam seu ritmo de crescimento (direta e indiretamente) -, essa relação não é tão direta como ocorre com a receita. As despesas apresentam maior grau de rigidez e menor sensibilidade aos ciclos econômicos. Tanto é assim que, exceto raras exceções, não sofrem ajustamento ao ciclo nas metodologias de cálculo do resultado estrutural. Por isso, como forma alternativa de avaliar a política fiscal na fase recente, iremos comparar as taxas de crescimento das despesas primárias dos últimos dezesseis anos.

\section{O CICLO DE CONTRAÇÃO E EXPANSÃO EM PERSPECTIVA}

O ciclo de política fiscal iniciado com a introdução do regime de metas em 1999, como salientado anteriormente, pode ser dividido em duas fases, uma contracionista e outra expansionista. Embora a flexibilização do superavit primário tenha se iniciado entre 2005 e 2006, podemos, grosso modo, associá-la à fase contracionista aos governos FHC II (1999-2002) e Lula I (2003-2006) e à fase expansionista aos governos Lula II (20072010) e Dilma I (2011-2014), e assim comparar as taxas de crescimento médio das despesas em cada período.

Nesta fase da análise, vamos nos concentrar no governo central, para o qual é possível construir uma série de razoável qualidade para todos os agregados das despesas. Reunindo-se as despesas em cinco grandes grupos, foi calculada a taxa média anual de crescimento de três formas diferentes: i) valores nominais; ii) valores corrigidos pelo deflator implícito do PIB; e iii) valores corrigidos pelo Índice Nacional de Preços ao Consumidor Amplo (IPCA/IBGE) médio. 
Os resultados elencados na Tabela 4 mostram, em primeiro lugar, que, no agregado, o ritmo médio de crescimento da despesa primária - medido em valores nominais ou reais - pouco se altera ao longo deste ciclo mais longo da política fiscal. Uma possível objeção a tal constatação é a possibilidade das taxas de crescimento no período Dilma I estarem subestimadas por não incluírem determinadas despesas não explicitadas no resultado primário do Tesouro Nacional. Por isso, a Tabela 5 apresenta as principais despesas não explícitas (rolagens de pagamentos e subsídios ao BNDES) ${ }^{18}$, e as taxas de crescimento foram recalculadas com esse ajuste na Tabela 4. Essas despesas não explícitas aumentaram o patamar das despesas em R \$ 15,2 bilhões no ano de 2010 e R\$22,3 bilhões em 2014, mas não modificam as taxas de crescimento do total das despesas no período Dilma I. O que se altera para cima, isso sim, são as taxas de crescimento no período Lula II, que passa de $4,9 \%$ para $5,5 \%$ quando consideradas as taxas reais pelo deflator do PIB.

De todo modo, o resultado pouco modificou a essência das conclusões anteriores: as taxas médias (ajustadas) de crescimento da despesa primária, seja em valores nominais ou reais, não se alteram tanto ao longo do ciclo mais longo da política fiscal. Isso sugere que as variações do resultado primário (em proporção do PIB) foram determinadas principalmente pelas variações no ritmo de crescimento econômico e nas taxas de crescimento das receitas.

A rigidez das taxas de crescimento das despesas primárias se deve principalmente ao comportamento dos benefícios sociais. É absolutamente notável que as taxas de crescimento da despesa de benefícios sociais não só foram altas ao longo de todo o ciclo da política fiscal, mas inclusive mais altas na fase contracionista - especialmente no governo Lula I, mas também no governo FHC II. Esse diferencial de taxas de crescimento não é afetado pela retirada do programa Bolsa Família do agregado; ou seja, esse padrão de evolução deriva principalmente dos demais benefícios previdenciários e assistenciais, vinculados majoritariamente ao salário mínimo. Este ponto será retomado com mais profundidade na próxima seção.

\footnotetext{
18 As rolagens de pagamentos são despesas reconhecidas no exercício-fiscal e inscritas em restos a pagar processados ou pagas por ordens bancárias a serem debitadas nos exercícios seguintes. Não consideram as inscrições em restos a pagar não processados, relativas a despesas não reconhecidas que não criam obrigação de pagamento (ver Gobetti, 2006; e Orair, 2011). Já os subsídios implícitos ao BNDES são apurados pela diferença entre o custo de captação dos repasses do TN ao BNDES e o montante que retorna ao TN pelos pagamentos do BNDES. Os subsídios explícitos - por exemplo, no Programa de Sustentação do Investimento (PSI), que financia a taxas de juros inferiores às praticadas pelo BNDES - já estão considerados na rubrica subsídios da Tabela 4. Ressalve-se que não foi possível contar com informações de montantes não repassados às empresas estatais (BNDES ou Caixa Econômica Federal, que intermediam programas como PSI, MCMV e benefícios sociais), que podem constituir uma fonte adicional de despesa não explícita no resultado primário.
} 
A análise das taxas de crescimento real da despesa de pessoal é interessante porque indica um padrão diferenciado de ciclo, mais curto, em que a cada quatro anos se alternam contrações e expansões. Curiosamente, o período de governo considerado fiscalmente mais expansionista (Dilma II) foi o que registrou a menor taxa de crescimento real da despesa com salários e aposentadorias de servidores públicos.

Tabela 4 - Taxas médias de crescimento das despesas e das receitas, 1999-2014 (em \%)

\begin{tabular}{|c|c|c|c|c|}
\hline Discriminação & 1999-2002 & 2003-2006 & 2007-2010 & 2011-2014 \\
\hline \multicolumn{5}{|l|}{ Receita total } \\
\hline Taxa nominal & 14,9 & 14,1 & 11,7 & 9,3 \\
\hline Taxa real-deflator & 6,5 & 4,8 & 3,6 & 2,2 \\
\hline Taxa real-IPCA & 7,6 & 5,6 & 6,5 & 3,0 \\
\hline \multicolumn{5}{|l|}{ Despesa total } \\
\hline Taxa nominal & 12,1 & 14,6 & 13,1 & 11,4 \\
\hline Taxa real-deflator & 3,9 & 5,2 & 4,9 & 4,2 \\
\hline Taxa real-IPCA & 5,0 & 6,1 & 7,9 & 5,0 \\
\hline \multicolumn{5}{|l|}{ Despesa total ajustada } \\
\hline Taxa nominal & 12,1 & 14,6 & 13,7 & 11,4 \\
\hline Taxa real-deflator & 3,9 & 5,2 & 5,5 & 4,2 \\
\hline Taxa real-IPCA & 5,0 & 6,1 & 8,5 & 4,9 \\
\hline \multicolumn{5}{|l|}{ Pessoal } \\
\hline Taxa nominal & 12,6 & 10,4 & 12,1 & 7,2 \\
\hline Taxa real-deflator & 4,4 & 1,3 & 4,0 & 0,2 \\
\hline Taxa real-IPCA & 5,5 & 2,2 & 7,0 & 1,0 \\
\hline \multicolumn{5}{|l|}{ Benefícios sociais } \\
\hline Taxa nominal & 14,3 & 18,7 & 12,6 & 12,5 \\
\hline Taxa real-deflator & 5,9 & 9,0 & 4,4 & 5,2 \\
\hline Taxa real-IPCA & 7,0 & 9,9 & 7,4 & 6,0 \\
\hline \multicolumn{5}{|l|}{ Custeio de capital } \\
\hline Taxa nominal & 8,3 & 12,2 & 15,2 & 13,3 \\
\hline Taxa real-deflator & 0,4 & 3,0 & 6,8 & 6,0 \\
\hline Taxa real-IPCA & 1,4 & 3,9 & 9,9 & 6,7 \\
\hline \multicolumn{5}{|l|}{ Custeio } \\
\hline Taxa nominal & 9,7 & 11,5 & 13,2 & 12,7 \\
\hline Taxa real-deflator & 1,7 & 2,4 & 5,0 & 5,4 \\
\hline Taxa real-IPCA & 2,7 & 3,2 & 8,0 & 6,1 \\
\hline \multicolumn{5}{|l|}{ Investimento } \\
\hline Taxa nominal & 8,4 & 5,7 & 30,8 & 6,4 \\
\hline Taxa real-deflator & 0,5 & $-3,0$ & 21,4 & $-0,5$ \\
\hline Taxa real-IPCA & 1,5 & $-2,2$ & 24,8 & 0,2 \\
\hline \multicolumn{5}{|l|}{ Inversões e subsídios } \\
\hline Taxa nominal & $-2,7$ & 31,5 & $-0,6$ & 35,2 \\
\hline Taxa real-deflator & $-9,8$ & 20,7 & $-7,8$ & 26,4 \\
\hline Taxa real-IPCA & $-8,9$ & 21,7 & $-5,2$ & 27,3 \\
\hline Taxa crescimento PIB & 2,3 & 3,5 & 4,5 & 2,1 \\
\hline
\end{tabular}

Fonte: Elaboração própria. 
Tabela 5 - Despesas não explicitadas no resultado primário, 2006-2014 (em milhões de R\$)

\begin{tabular}{lccccccccc}
\hline Despesas & $\mathbf{2 0 0 6}$ & $\mathbf{2 0 0 7}$ & $\mathbf{2 0 0 8}$ & $\mathbf{2 0 0 9}$ & $\mathbf{2 0 1 0}$ & $\mathbf{2 0 1 1}$ & $\mathbf{2 0 1 2}$ & $\mathbf{2 0 1 3}$ & $\mathbf{2 0 1 4}$ \\
\hline Subsídios ao BNDES & 299 & 223 & 624 & 1,831 & 7,946 & 10,538 & 12,343 & 10,629 & 21,267 \\
Efeito ordens bancárias $^{* *}$ & -395 & $-1,410$ & 422 & 3,014 & 4,524 & 1,190 & 4,818 & 3,665 & $-3,740$ \\
Efeito restos a pagar** & 1,343 & 113 & 0 & $-2,185$ & 2,793 & -550 & 2,183 & 7,332 & 4,841 \\
\hline Total & $\mathbf{- 9 6}$ & $\mathbf{- 1 , 1 8 7}$ & $\mathbf{1 , 0 4 7}$ & $\mathbf{2 , 6 6 0}$ & $\mathbf{1 5 , 2 6 3}$ & $\mathbf{1 1 , 1 7 8}$ & $\mathbf{1 9 , 3 4 4}$ & $\mathbf{2 1 , 6 2 6}$ & $\mathbf{2 2 , 3 6 9}$ \\
\hline
\end{tabular}

Notas: (*) Estimado pela SPE entre 2009 e 2014 e pelos autores entre 2006 e 2008 com base no volume médio de empréstimos. ${ }^{* *}$ ) Estimado pelos autores a partir da diferença entre as despesas pagas no SIAFI e no RTN. (***) Estimado pela variação do estoque de restos a pagar processados.

Fonte: Elaboração própria com base em dados da STN/MF, SIAFI e SPE/MF.

A discricionariedade da política fiscal irá refletir-se efetivamente nas taxas de crescimento das despesas de custeio, investimentos e subsídios, tanto nas contrações quanto nas expansões. Contudo, alguns aspectos particulares merecem atenção: os investimentos, como se pode observar na Tabela 4, foram fortemente ativados no início da fase de expansão, durante o governo Lula II, mas depois disso permaneceram estagnados e em contração no governo Dilma I, quando o expansionismo fiscal foi canalizado principalmente para os subsídios, aí incluídos os gastos do MCMV.

O gasto de custeio, que envolve desde a manutenção da máquina administrativa até o financiamento dos serviços de saúde e educação, por seu turno, tem apresentado uma aceleração gradual ao longo de todo o ciclo, sugerindo que existem também fatores estruturais por trás de sua evolução. A cada período de governo, as taxas reais de crescimento do gasto de custeio são elevadas, estando no momento em 5,4\% ao ano (a.a.). Na fase de contração (FHC II e Lula I), essas taxas eram menores que o ritmo de crescimento da economia. Por isso, a despesa de custeio encolhia em proporção do PIB, enquanto na fase expansionista as taxas se tornaram mais elevadas e, então, temos um crescimento em proporção do PIB.

Devemos observar que o ritmo de crescimento real das despesas, no agregado, pouco se alterou entre os governos Lula II e Dilma I, tendo inclusive se desacelerado nesse último governo: de 4,9\% (ou 5,5\% se for considerado o ajuste das despesas não explícitas) para 4,2\%.Ao mesmo tempo, as receitas tributárias e mesmo o agregado das receitas primárias permaneceram relativamente estabilizados em proporção do PIB (Gráfico 1). Mas a queda na taxa média de crescimento da economia (de 4,5\% para $2,1 \%)$ fez toda a diferença sobre os indicadores fiscais. Embora os indicadores de impulso fiscal derivados da variação do resultado estrutural indiquem que o período de 2011-2014 seja mais expansionista que 2007-2010, as taxas de crescimento das despesas não indicam claramente isso.

Mesmo a taxa média real de crescimento do componente de custeio e capital (incluindo subsídios explícitos, mas não os implícitos do BNDES), que melhor reflete a 
orientação da política fiscal, regrediu de $6,8 \%$ para $6,0 \%$ (ou de $9,9 \%$ para $6,7 \%$, utilizando-se o IPCA médio como deflator) entre os governos Lula II e Dilma I. Isso nos leva a concluir que o impacto da desaceleração econômica sobre a deterioração dos indicadores fiscais de resultado é maior que o presumido convencionalmente. Portanto, é preciso muita cautela para que o atual ajuste fiscal não agrave o quadro econômico e não dificulte ainda mais o reequilíbrio fiscal.

Por fim, cabe salientar que a evolução do resultado primário não diz tudo sobre o expansionismo fiscal, uma vez que, como vimos, não reflete na plenitude toda a política de subsídios e desonerações tributárias ativada desde 2008/2009. Isso reforça a necessidade de desenvolver abordagens mais amplas para avaliar a orientação da política fiscal.

\section{A DINÂMICA DOS BENEFíCIOS SOCIAIS E O DESAFIO DA SUSTENTABILIDADE FISCAL}

A análise do ciclo de política fiscal iniciado após 1999 já sugeriu quão rígida é a despesa primária e, em particular, o quanto essa rigidez provém da dinâmica dos gastos com benefícios sociais (previdenciários ou assistenciais). Estes cresceram de 5,86\% do PIB, em 1998, para 6,74\% do PIB, em 2002; 8,28\% do PIB, em 2006; e 9,29\% do PIB, em 2014, como podemos ver na Tabela 6. Dessa expansão, cerca de 60\% ocorreu entre os benefícios previdenciários do Instituto Nacional do Seguro Social (INSS). Os 40\% restantes são explicados em proporções semelhantes pelas demais categorias de benefícios sociais: os benefícios assistenciais de prestação continuada - no âmbito da Lei Orgânica da Assistência Social (LOAS) e Renda Mensal Vitalícia (RMV) -; o abono salarial e o seguro-desemprego; e o Bolsa Família.

Costumeiramente, essa dinâmica dos benefícios sociais é atribuída aos aumentos do salário mínimo, que serve de piso de referência para os programas previdenciários e assistenciais (exceto o Bolsa Família). De fato, a regra de reajuste do salário mínimo, baseada na correção da inflação mais um ganho real equivalente ao crescimento do PIB, explica parte importante desse fenômeno, mas não é o único nem o principal determinante.

Tabela 6 - Despesas com benefícios sociais do governo central, por categoria, 1998-2014 (em \% do PIB)

\begin{tabular}{lcccccccc}
\hline Benefícios & $\mathbf{1 9 9 8}$ & $\mathbf{2 0 0 2}$ & $\mathbf{2 0 0 6}$ & $\mathbf{2 0 1 0}$ & $\mathbf{2 0 1 1}$ & $\mathbf{2 0 1 2}$ & $\mathbf{2 0 1 3}$ & $\mathbf{2 0 1 4}$ \\
\hline Previdenciários (INSS) & 5,15 & 5,79 & 6,87 & 6,56 & 6,43 & 6,72 & 6,92 & 7,14 \\
Assistenciais (LOAS-RMV) & 0,27 & 0,34 & 0,48 & 0,57 & 0,57 & 0,62 & 0,65 & 0,70 \\
Abono salarial e Seguro-desemprego & 0,44 & 0,48 & 0,61 & 0,77 & 0,78 & 0,82 & 0,86 & 0,98 \\
Bolsa Família/Escola & 0,00 & 0,13 & 0,32 & 0,35 & 0,38 & 0,45 & 0,47 & 0,47 \\
\hline Total & $\mathbf{5 , 8 6}$ & $\mathbf{6 , 7 4}$ & $\mathbf{8 , 2 8}$ & $\mathbf{8 , 2 4}$ & $\mathbf{8 , 1 6}$ & $\mathbf{8 , 6 1}$ & $\mathbf{8 , 8 9}$ & $\mathbf{9 , 2 9}$ \\
\hline
\end{tabular}

Fonte: Elaboração própria com base em dados de Gobetti (2015). 
Tabela 7 - Evolução da quantidade de beneficiários por modalidade, 2004-2014

\begin{tabular}{ccccc}
\hline Benefícios & Previdenciários & LOAS/RMV & Seguro-desemprego & Total \\
\hline 2004 & $20,506,649$ & $2,629,196$ & $5,008,168$ & $28,144,013$ \\
2005 & $21,149,560$ & $2,792,638$ & $5,582,395$ & $29,524,593$ \\
2006 & $21,644,885$ & $2,940,141$ & $6,058,355$ & $30,643,381$ \\
2007 & $22,066,263$ & $3,096,566$ & $6,525,294$ & $31,688,123$ \\
2008 & $22,776,205$ & $3,311,827$ & $7,215,675$ & $33,303,707$ \\
2009 & $23,534,497$ & $3,504,080$ & $7,911,598$ & $34,950,175$ \\
2010 & $24,426,882$ & $3,703,505$ & $8,117,808$ & $36,248,195$ \\
2011 & $25,176,323$ & $3,863,503$ & $8,515,204$ & $37,555,030$ \\
2012 & $26,032,855$ & $3,999,462$ & $8,779,654$ & $38,811,971$ \\
2013 & $27,009,011$ & $4,165,956$ & $9,114,189$ & $40,289,156$ \\
2014 & $27,818,973$ & $4,310,448$ & $9,060,184$ & $41,189,605$ \\
\hline Taxa Média de Crescimento & $\mathbf{3 , 1}$ & $\mathbf{5 , 0}$ & $\mathbf{6 , 1}$ & $\mathbf{3 , 9}$ \\
\hline
\end{tabular}

Fonte: Elaboração própria com base nas estatísticas dos Ministérios da Previdência e do Trabalho.

O principal fator por trás da ampliação desse gasto é o crescimento vegetativo do número de beneficiários, seja pelos direitos assegurados constitucionalmente, que foram progressivamente sendo acionados, seja pelas pressões demográficas ou pelo efeito da formalização do mercado de trabalho. Independentemente das causas, o fato é que o número de beneficiários cresceu a uma taxa média de quase $4 \%$ a.a. em pouco mais de uma década, conforme se vê na Tabela 7.

Fica fácil compreender por que, com tal taxa de crescimento, mesmo que os benefícios fossem corrigidos apenas pela inflação (como ocorre com 38\% dos benefícios previdenciários), o cenário mais provável seria de expansão da despesa em proporção do PIB. Tudo dependeria, evidentemente, de a taxa de crescimento da economia ser maior ou menor que a taxa de crescimento vegetativo.

É difícil prever se as taxas de expansão dos beneficiários verificadas nos últimos dez anos se manterão pela próxima década, e em qual magnitude poderiam ser afetadas por algumas das reformas em debate. Mas mesmo exercícios de simulações utilizando cenários otimistas sugerem resultados preocupantes, como podemos ver na Tabela 8. Essa tabela apresenta simulações simples, a partir de cenários com parâmetros distintos para as taxas de crescimento da economia $(g)$, inflação (def) e quantidade de beneficiários, e com duas alternativas de regras de reajuste do salário mínimo que consideram a atual indexação ao crescimento do PIB e a recente proposta de modificar o indexador para PIB per capita ${ }^{19}$.

\footnotetext{
19 Parâmetros projetados para 2016 em diante. Em 2015, considerou-se inflação de 8\% e crescimento do PIB de $-1 \%$, com base nas estimativas de meados do ano, posteriormente revisadas, mas que não alteram qualitativamente os resultados. As mudanças na legislação foram consideradas apenas a partir de 2016.
} 
Sob a atual regra de reajuste do mínimo e com a economia continuando a crescer a uma média de $1,5 \%$ a 2,5\% a.a., esse exercício de simulação sugere que o gasto com benefícios sociais tende a crescer entre 2,3 p.p. e 2,8 p.p. do PIB nos próximos dez anos. Serão exigidos expressivos aumentos de carga tributária, equivalentes a duas novas Contribuições Provisórias sobre Movimentação Financeira (CPMFs), se o objetivo for neutralizar o efeito dessa despesa sobre o resultado primário.

Se a economia deslanchar e voltar a crescer à taxa de 4,5\%, como ocorreu entre 2007 e 2010, ainda assim a despesa com benefícios sociais cresceria 1,3 p.p. do PIB na ausência de outras mudanças. Talvez o impacto orçamentário de uma expansão desta magnitude, com alto crescimento econômico, possa ser neutralizado à medida que as receitas previdenciárias continuem crescendo também acima do PIB, mas se trata de uma aposta de muito risco.

Vale dizer que o caráter otimista desses cenários se deve não somente às perspectivas sobre aceleração do crescimento econômico, mas também sobre a desaceleração do quantitativo de beneficiários. Isso fica muito evidente quando se observa que as projeções do IBGE apontam para a ampliação da população de idosos no país em cerca de 9,8 milhões no período 2014-2024 (de 19,5 milhões para 29,2 milhões) ${ }^{20}$.

Essa restrição demográfica já estabelece um piso de $2,2 \%$ para a taxa de crescimento do quantitativo de benefícios sociais na próxima década. Uma eventual desaceleração da taxa de crescimento vegetativo dos benefícios sociais para $3 \%$ a.a. exigiria uma queda muito acentuada, e mesmo indesejável, no crescimento dos demais benefícios que não têm relação direta com a população idosa (seguro-desemprego, aposentadoria por invalidez, pensão por morte, auxílio-doença, assistência aos portadores de invalidez etc.). Seria necessário passar das taxas próximas a $4,1 \%$ verificadas nos anos 2004-2014 para 1,8\% na década seguinte.

Tabela 8 - Projeção para as despesas com benefícios sociais, 2014-2024 (em \%)

\begin{tabular}{|c|c|c|c|c|}
\hline \multirow{2}{*}{ Ano } & \multicolumn{4}{|c|}{ Padrão de crescimento de beneficiários dos últimos dez anos e atual regra de reajuste do salário mínimo } \\
\hline & $\mathrm{g}=1,5 \% ; \mathrm{def}=5 \%$ & $\mathrm{~g}=2,5 \% ; \mathrm{def}=5 \%$ & $\mathrm{~g}=3,5 \% ; \mathrm{def}=5 \%$ & $\mathrm{~g}=4,5 \% ; \mathrm{def}=6 \%$ \\
\hline 2014 & 8,6 & 8,6 & 8,6 & 8,6 \\
\hline 2015 & 9,0 & 9,0 & 9,0 & 9,0 \\
\hline 2016 & 9,3 & 9,2 & 9,1 & 8,9 \\
\hline 2017 & 9,4 & 9,2 & 9,1 & 8,8 \\
\hline 2018 & 9,7 & 9,4 & 9,2 & 9,0 \\
\hline 2019 & 9,9 & 9,7 & 9,4 & 9,1 \\
\hline 2020 & 10,2 & 9,9 & 9,6 & 9,2 \\
\hline 2021 & 10,5 & 10,1 & 9,8 & 9,4 \\
\hline
\end{tabular}

(continua)

\footnotetext{
${ }^{20}$ Considera-se a população de mulheres com idade a partir de 60 anos e homens a partir de 65 anos.
} 
Tabela 8 - Projeção para as despesas com benefícios sociais, 2014-2024 (em \%) (continuação)

\begin{tabular}{|c|c|c|c|c|}
\hline \multirow{2}{*}{ Ano } & \multicolumn{4}{|c|}{ Padrão de crescimento de beneficiários dos últimos dez anos e atual regra de reajuste do salário mínimo } \\
\hline & $\mathrm{g}=1,5 \% ; \mathrm{def}=5 \%$ & $\mathrm{~g}=2,5 \% ; \mathrm{def}=5 \%$ & $\mathrm{~g}=3,5 \% ; \mathrm{def}=5 \%$ & $\mathrm{~g}=4,5 \% ; \mathrm{def}=6 \%$ \\
\hline 2022 & 10,8 & 10,4 & 10,0 & 9,6 \\
\hline 2023 & 11,1 & 10,6 & 10,2 & 9,7 \\
\hline 2024 & 11,4 & 10,9 & 10,4 & 9,9 \\
\hline$\Delta 2014-24$ & 2,8 & 2,3 & 1,8 & 1,3 \\
\hline
\end{tabular}

\begin{tabular}{|c|c|c|c|c|}
\hline \multirow{2}{*}{ Ano } & \multicolumn{4}{|c|}{ Crescimento de beneficiários de $3 \%$ a.a. e atual regra de reajuste do salário mínimo } \\
\hline & $\mathrm{g}=1,5 \% ; \mathrm{def}=5 \%$ & $\mathrm{~g}=\mathbf{2 , 5} \% ; \mathrm{def}=5 \%$ & $\mathrm{~g}=3,5 \% ; \mathrm{def}=5 \%$ & $\mathrm{~g}=4,5 \% ; \mathrm{def}=6 \%$ \\
\hline 2014 & 8,6 & 8,6 & 8,6 & 8,6 \\
\hline 2015 & 9,0 & 9,0 & 9,0 & 9,0 \\
\hline 2016 & 9,2 & 9,1 & 9,0 & 8,9 \\
\hline 2017 & 9,3 & 9,2 & 9,0 & 8,8 \\
\hline 2018 & 9,6 & 9,3 & 9,1 & 8,8 \\
\hline 2019 & 9,8 & 9,5 & 9,2 & 8,9 \\
\hline 2020 & 10,0 & 9,7 & 9,4 & 9,0 \\
\hline 2021 & 10,2 & 9,9 & 9,5 & 9,1 \\
\hline 2022 & 10,5 & 10,1 & 9,7 & 9,2 \\
\hline 2023 & 10,7 & 10,2 & 9,8 & 9,3 \\
\hline 2024 & 11,0 & 10,4 & 10,0 & 9,5 \\
\hline$\Delta 2014-24$ & 2,3 & 1,8 & 1,3 & 0,8 \\
\hline
\end{tabular}

\begin{tabular}{|c|c|c|c|c|}
\hline \multirow{2}{*}{ Ano } & \multicolumn{4}{|c|}{ Crescimento de beneficiários de $3 \%$ a.a. e nova regra para o salário mínimo } \\
\hline & $\mathrm{g}=1,5 \% ; \mathrm{def}=5 \%$ & $\mathrm{~g}=2,5 \%$; def $=5 \%$ & $\mathrm{~g}=3,5 \% ; \mathrm{def}=5 \%$ & $\mathrm{~g}=4,5 \% ; \mathrm{def}=6 \%$ \\
\hline 2014 & 8,6 & 8,6 & 8,6 & 8,6 \\
\hline 2015 & 9,0 & 9,0 & 9,0 & 9,0 \\
\hline 2016 & 9,2 & 9,1 & 9,0 & 8,9 \\
\hline 2017 & 9,3 & 9,1 & 9,0 & 8,7 \\
\hline 2018 & 9,4 & 9,2 & 9,0 & 8,7 \\
\hline 2019 & 9,6 & 9,3 & 9,1 & 8,8 \\
\hline 2020 & 9,8 & 9,5 & 9,2 & 8,8 \\
\hline 2021 & 10,0 & 9,6 & 9,3 & 8,9 \\
\hline 2022 & 10,2 & 9,7 & 9,4 & 8,9 \\
\hline 2023 & 10,3 & 9,9 & 9,4 & 9,0 \\
\hline 2024 & 10,5 & 10,0 & 9,5 & 9,1 \\
\hline$\Delta 2014-24$ & 1,9 & 1,4 & 0,9 & 0,4 \\
\hline
\end{tabular}

Notas: (1) Exclusive Bolsa Família e pagamento de sentenças judiciais. (2) Taxa de crescimento da economia $(g)$ e inflação (def).

Fonte: Elaboração própria.

Caso a taxa de crescimento vegetativo fosse reduzida para $3 \%$, por exemplo, ainda assim a despesa continuaria crescendo muito, com baixo crescimento econômico, mesmo diante da possibilidade de alteração da regra de reajuste do salário mínimo. Acréscimos menos pronunciados na despesa de benefícios sociais (inferiores a 1\% do PIB), com possibilidade mais concreta de neutralização dos seus impactos orçamentários (via expansão das receitas previdenciárias), somente se verificam nos cenários muito otimistas: crescimento econômico de $4,5 \%$ a.a., com queda da taxa de cresci- 
mento vegetativo para 3\%; ou crescimento econômico igual ou superior a 3,5\%, com crescimento vegetativo de $3 \%$ e mudança na regra de reajuste do salário mínimo.

Esses exercícios de simulação, admitidamente simplificados, são úteis para ilustrar que a rigidez das despesas com benefícios sociais tende a se perpetuar nos próximos anos e restringir a margem de atuação da política fiscal. Também sugerem a necessidade de se avançar em uma agenda de reformas que consiga sensibilizar os parâmetros cruciais da equação de expansão - a quantidade de benefícios e a regra de indexação do salário mínimo.

Suscitar esse debate não implica negligenciar o papel crucial que a expansão da cobertura dos benefícios sociais desempenhou no processo de redução da desigualdade na distribuição de renda e, mais geralmente, no aumento do bem-estar de parcela considerável da sociedade brasileira nos últimos anos; muito pelo contrário. É crucial para a continuidade desse processo que tal agenda de reformas não seja pautada exclusivamente em critérios restritos à mera busca de equilíbrio financeiro da seguridade social, mas sim em critérios de equidade orientados para a eliminação das suas inúmeras distorções e para a manutenção do caráter universal de acesso aos serviços da proteção social básica. Além disso, há a necessidade de que esta agenda de reformas contemple ações adicionais, como mudanças no arcabouço tributário que reduzam o alto grau de regressividade da estrutura tributária brasileira. A ênfase da ação distribuidora do setor público deve ser reorientada do gasto para a tributação, pois a orientação atual já vem mostrando sinais de esgotamento.

O que fazer para viabilizar isso? É mais fácil responder o que não fazer: um ajuste que penalize os investimentos públicos, onere excessivamente o assalariado e enfraqueça não só a economia, mas as chances de um acordo político para aprovar medidas estruturais no Congresso.

\section{CONSIDERAÇÕES FINAIS}

Este estudo oferece uma contribuição para o debate sobre as mudanças no regime fiscal brasileiro, na medida em que apresenta uma série acima da linha para o resultado primário das administrações públicas. Isto permite compreender melhor a recente fase de expansionismo fiscal, identificando não só seus determinantes em termos de receitas e despesas, mas também o componente derivado dos governos estaduais e municipais.

Os dados mostram, em primeiro lugar, que os principais vetores impulsionadores das despesas, responsáveis por sua elevada rigidez, são muito anteriores ao período pós-crise de 2008 - as taxas de crescimento acima do PIB dos benefícios sociais, na esfera federal, e dos gastos com pessoal, na esfera subnacional. A principal caracterís- 
tica distintiva do período mais recente de expansão fiscal, em relação àquele que se estendeu até 2010, diz respeito aos instrumentos fiscais utilizados. Antes foram mais os investimentos públicos e no período mais recente foram mais os subsídios e outros gastos correntes (além das desonerações). Isso indica uma importante mudança na composição da política fiscal.

$\mathrm{Na}$ esfera federal, a taxa real de crescimento médio das despesas de custeio e investimento - incluindo subsídios explícitos, como os do programa MCMV, mas não os implícitos do BNDES -, que melhor reflete a orientação da política fiscal, se alterou muito pouco ao longo da fase expansionista da política fiscal e inclusive mostrou ligeira desaceleração quando se comparam os subperíodos 2007-2010 e 2011-2014. Porém, como o primeiro subperíodo expansionista coincidiu com crescimento econômico mais acelerado, e o subperíodo mais recente, com um baixo crescimento econômico, o resultado foi uma deterioração significativa dos indicadores fiscais.

Tais evidências contribuem para a literatura por permitirem um olhar mais qualificado e elucidarem certas características da política fiscal no Brasil, na linha de estudos como a de Barbosa-Filho e Souza (2010) e Lopreato (2014), que analisam a orientação da política fiscal e a flexibilização fiscal promovida desde 2006. Espera-se contribuir também para o debate em curso no país, que vem questionando em que medida os instrumentos de política fiscal utilizados no mais recente subperíodo da fase de expansão fiscal - subsídios e desonerações em detrimento de investimentos, cujos efeitos na demanda agregada são diretos - não foram inapropriados para sustentar o crescimento $^{21}$.

Por fim, o estudo oferece uma contribuição adicional ao mostrar que o indicador tradicional para mensurar o impulso fiscal, que é a variação do resultado estrutural ajustado ao ciclo econômico (abordagem top-down ou de cima para baixo), tem subestimado o expansionismo pelo lado da política tributária e superestimado pelo lado das despesas. Isto tende a enviesar as estimativas de multiplicadores fiscais, relevantes para uma análise mais qualificada da política fiscal. Tal viés decorre, como salientado no estudo, de problemas nas estimativas das elasticidades de curto prazo das receitas, que não captam apropriadamente as assimetrias em relação ao ciclo ou os fatores autônomos em relação ao produto que influenciam a arrecadação.

Esse problema também tem sido discutido na literatura internacional sobre multiplicadores fiscais. É o caso de Guajardo, Leigh e Pescatori (2011), que mostram que os resultados de Alesina e Perotti (1995) e Alesina e Ardagna (1998) sobre a prevalência de efeitos não keynesianos na política fiscal foram conduzidos pela escolha da abordagem de cima para baixo. Perotti (2011) mostra que as estimativas dos multiplicadores

\footnotetext{
${ }^{21}$ Ver Serrano e Summa (2012) e Paula, Modenesi e Pires (2015).
} 
podem ser enviesadas na presença de variáveis de tendência que não são apropriadamente levadas em consideração.

A alternativa que tem ganhado proeminência na literatura internacional desde Romer e Romer $(2008,2010)$ é a chamada abordagem narrativa ou bottom-up (de baixo para cima). Ela consiste em mensurar o esforço fiscal pela soma das medidas fiscais discricionárias (ou exógenas) introduzidas pelos governos com base nas estimativas de impactos orçamentários atribuídos pelas autoridades fiscais no momento de sua adoção. Devries et al. (2012), por exemplo, adotam um enfoque histórico em que analisam as intenções e as ações descritas nos relatórios orçamentários e nos documentos contemporâneos de políticas públicas, e extraem deles as informações sobre impactos orçamentários.

Uma extensão natural deste trabalho, portanto, será investir nesse tipo de abordagem ou em uma abordagem mista para tentar obter uma medida mais precisa das ações discricionárias de flexibilização ou contenção fiscal perseguidas pelo governo. Uma segunda linha de avanços é incorporar indicadores que mensuram os impactos das diferentes alternativas de composição das receitas e das despesas sobre a demanda agregada e o produto - e não somente avaliar a orientação da política fiscal a partir da medida de impulso fiscal -, a exemplo de estudos como os de Macedo e Silva (2005), Lara, Rodrigues e Bastos (2015) e Serrano (2014). Cremos que esse futuro trabalho pode proporcionar insumos relevantes para melhores avaliações dos multiplicadores fiscais e da política fiscal no Brasil.

\section{REFERÊNCIAS}

AFONSO, J. R.; GOBETTI, S. W. Impactos das reformas tributária e do gasto público sobre o crescimento e os investimentos: o caso do Brasil. Santiago do Chile: Cepal, 2015. (Serie Macroeconomía del Desarrollo). No prelo.

ALESINA, A.; ARDAGNA, S. Tales of fiscal adjustment. Economic Policy, v. 13, n. 27, p. 489-585, 1998.

ALESINA, A.; PEROTTI, R. Fiscal expansions and fiscal adjustments in OECD countries. Economic Policy, v. 10, n. 21, p. 205-248, 1995.

BARBOSA-FILHO, N.; SOUZA, J. A. P. "A Inflexão do governo Lula: política econômica, crescimento e distribuição de renda". In: SADER, E.; GARCIA, M. A. (Org.). Brasil: entre o passado e o futuro. São Paulo: Fundação Perseu Abramo; Boitempo, 2010.

BRASIL. Ministério da Fazenda. Monitor de política fiscal: resultado fiscal estrutural - metodologia proposta para o Brasil. Brasília: SPE, dez. 2014.

DEVRIES, P. et al. A new action-based dataset of fiscal consolidation. IMF Working Paper Series, n. 11128, 2011.

GIAMBIAGI, F. 18 Anos de Política Fiscal no Brasil. EconomiaAplicada, v. 12, n. 4, p. 535580,2008 . 
GIAVAZZI, F.; PAGANO, M. Can severe fiscal contractions be expansionary? Tales of two small European countries. NBER Working Paper Series, n. 3372, 1990.

GOBETTI, S. W. Estimativa dos Investimentos Públicos: um novo modelo de análise da execução orçamentária aplicado às contas nacionais. XI Prêmio Tesouro Nacional de Monografias, 2006.

GOBETTI, S. W. Ajuste fiscal no Brasil: os limites do possível. Texto para Discussão, Ipea, Brasília, n. 2037, 2015.

GOBETTI, S.; GOUVÊA, R.; SCHETTINI, B. P. Resultado fiscal estrutural: um passo para a institucionalização de políticas anticíclicas no Brasil. Texto para Discussão, Ipea, Brasília, n. 1515, 2010.

GOBETTI, S. W.; ORAIR, R. Classificação e análise das despesas públicas federais pela ótica macroeconômica (2002-2009). Texto para Discussão, Ipea, Brasília, n. 1485, 2010.

GUAJARDO, J.; LEIGH, D.; PESCATORI, A. Expansionary austerity: new international evidence. IMF Working Paper, n. 11158, 2011.

LARA, F.; RODRIGUES, R.; BASTOS, C. As finanças públicas e o impacto fiscal entre 2003 e 2012: dez anos de governo do Partido dos Trabalhadores. Ensaios FEE, n. 36, v. 1, 2015.

LOPREATO, F. “Aspectos da atuação estatal de FHC a Dilma”. In: CALIXTRE, A.; BIANCARELLI, A.; CINTRA, M. A. M. (Org.). Presente e futuro do desenvolvimento brasileiro. Brasília: Ipea, 2014.

MACEDO E SILVA, A. C. O debate sobre o arranjo fiscal brasileiro: um pouco de aritmética keynesiana. Política Econômica em Foco, Campinas, n. 4, suplemento 7, 2005.

ORAIR, R. O. Especificidades do processo orçamentário brasileiro e os obstáculos à harmonização contábil: uma análise aplicada aos investimentos das administrações públicas. XVI Prêmio Tesouro Nacional de Monografias, 2011.

ORAIR, R. O. Desonerações em alta com rigidez da carga tributária: o que explica o paradoxo do decênio 2005-2014? Texto para Discussão, Ipea, Brasília, n. 2117, 2015.

ORENG, M. Superávit fiscal estrutural brasileiro. Texto para Discussão, Itaú, São Paulo, abr. 2011.

PAULA, L. F. de; MODENESI, A.; PIRES, M. The tale of the contagion of two crises and policy responses in Brazil: a case of (Keynesian) policy coordination. Journal of Post Keynesian Economics, v. 37, n. 3, p. 408-436, 2015.

PEROTTI, R. The "austerity myth": gain without pain? NBER Working Paper Series, n. 17571, 2011.

ROMER, C.; ROMER, D. A narrative analysis of postwar tax changes. Working Paper, University of California, Department of Economics, 2008.

ROMER, C.; ROMER, D. The macroeconomic effects of tax changes: estimates based on a new measure of fiscal shocks. American Economic Review, v. 100, n. 4, p. 763-801, 2010.

SCHETTINI, B. P. et al. Resultado estrutural e impulso fiscal: uma aplicação para as administrações públicas no Brasil - 1997-2010. Pesquisa e Planejamento Econômico, v. 41, n. 2, ago. 2011.

SERRANO, F. Efeitos multiplicadores de um superávit primário: um teorema do orçamento desequilibrado e a expansão recente da economia brasileira 2004-2011. Rio de Janeiro: 2014. Mimeo.

SERRANO, F.; SUMMA, R. A desaceleração rudimentar da economia brasileira desde 2011. Oikos, Rio de Janeiro, v. 11, n. 2, 2012. 


\section{APÊNDICE}

A estimativa das receitas ajustada ao ciclo econômico se dá a partir da seguinte fórmula de ajuste:

$$
R_{\text {ajustada }}=R_{\text {efetiva }} \times\left(P I B_{\text {tendencial }} / P I B_{\text {efetivo }}\right)^{\varepsilon}
$$

Para estimar quanto do componente cíclico das receitas foi transferido para as demais esferas de governo, utilizamos um modelo determinístico, calibrado de acordo com as regras vigentes e as proporções observadas, conforme disposto na Tabela A.2.

Tabela A.1 - Estimativa do componente cíclico das receitas, 2009-2014 (em R\$ milhões)

\begin{tabular}{|c|c|c|c|c|c|c|c|c|}
\hline \multirow{12}{*}{$\begin{array}{l}\text { Receitas } \\
\text { efetivas }\end{array}$} & Discriminação & Elasticidade & 2009 & 2010 & 2011 & 2012 & 2013 & 2014 \\
\hline & Receita tributária & 1,7 & 455,892 & 532,051 & 625,420 & 657,779 & 730,122 & 748,797 \\
\hline & PIS/Cofins & 2,0 & 147,966 & 180,892 & 205,292 & 218,988 & 248,941 & 246,296 \\
\hline & CSLL & 2,5 & 43,344 & 45,681 & 58,108 & 55,079 & 61,815 & 62,581 \\
\hline & IRPJ & 2,5 & 78,987 & 83,208 & 98,376 & 90,806 & 109,056 & 109,002 \\
\hline & IRRF+IRPF & 1,00 & 95,895 & 108,375 & 135,558 & 143,439 & 155,176 & 170,204 \\
\hline & IPI & 2,00 & 27,881 & 37,510 & 41,870 & 42,227 & 43,188 & 49,204 \\
\hline & Salário-educação & 0,60 & 9,589 & 11,049 & 13,115 & 14,775 & 16,562 & 18,301 \\
\hline & Outras & 0,00 & 52,230 & 65,337 & 73,100 & 92,465 & 95,383 & 93,208 \\
\hline & Receita previdenciária & 0,60 & 182,008 & 211,968 & 245,982 & 273,975 & 298,127 & 319,451 \\
\hline & ISS $^{*}$ & 0,90 & 25,432 & 30,543 & 35,656 & 41,567 & 45,213 & 51,059 \\
\hline & ICMS* & 1,30 & 227,830 & 265,564 & 295,147 & 323,279 & 360,717 & 382,037 \\
\hline \multirow{11}{*}{$\begin{array}{l}\text { Receitas } \\
\text { ajustadas }\end{array}$} & Receita tributária & & 477,049 & 524,549 & 611,299 & 645,551 & 722,782 & 764,823 \\
\hline & PIS/Cofins & & 156,206 & 177,786 & 199,656 & 217,628 & 245,835 & 252,868 \\
\hline & CSLL & & 46,382 & 44,702 & 56,121 & 54,652 & 60,853 & 64,675 \\
\hline & IRPJ & & 84,523 & 81,426 & 95,011 & 90,101 & 107,357 & 112,650 \\
\hline & IRRF+IRPF & & 98,528 & 107,441 & 133,684 & 142,993 & 154,205 & 172,460 \\
\hline & IPI & & 9,746 & 10,992 & 13,006 & 14,747 & 16,500 & 18,446 \\
\hline & Salário-educação & & 9,746 & 10,992 & 13,006 & 14,747 & 16,500 & 18,446 \\
\hline & Outras & & 52,230 & 65,337 & 73,100 & 92,465 & 95,383 & 93,208 \\
\hline & Receita previdenciária & & 184,992 & 210,870 & 243,847 & 273,463 & 297,006 & 321,985 \\
\hline & ISS* & & 26,060 & 30,306 & 35,212 & 41,450 & 44,958 & 51,668 \\
\hline & ICMS* & & 235,999 & 262,591 & 289,854 & 321,973 & 357,785 & 388,632 \\
\hline
\end{tabular}


Tabela A.1 - Estimativa do componente cíclico das receitas, 2009-2014 (em R\$ milhões) (continuação)

\begin{tabular}{|c|c|c|c|c|c|c|c|c|}
\hline \multirow{16}{*}{$\begin{array}{l}\text { Componente } \\
\text { cíclico }\end{array}$} & Discriminação & Elasticidade & 2009 & 2010 & 2011 & 2012 & 2013 & 2014 \\
\hline & Receita tributária & & $(21,157)$ & 7,502 & 14,121 & 3,228 & 7,340 & $(16,027)$ \\
\hline & PIS/Cofins & & $(8,240)$ & 3,106 & 5,636 & 1,360 & 3,107 & $(6,571)$ \\
\hline & CSLL & & $(3,038)$ & 978 & 1,987 & 427 & 963 & $(2,094)$ \\
\hline & IRPJ & & $(5,536)$ & 1,782 & 3,365 & 704 & 1,698 & $(3,647)$ \\
\hline & IRRF+IRPF & & $(2,634)$ & 934 & 1,874 & 446 & 971 & $(2,256)$ \\
\hline & IPI & & $(1,553)$ & 644 & 1,150 & 262 & 539 & $(1,313)$ \\
\hline & Salário-educação & & $(157)$ & 57 & 109 & 28 & 62 & $(145)$ \\
\hline & Outras & & - & - & - & - & - & - \\
\hline & Receita previdenciária & & $(2,983)$ & 1,098 & 2,045 & 512 & 1,121 & $(2,533)$ \\
\hline & ISS $^{*}$ & & $(628)$ & 237 & 444 & 116 & 255 & (609) \\
\hline & ICMS $^{*}$ & & $(8,168)$ & 2,973 & 5,293 & 1,307 & 2,932 & $(6,595)$ \\
\hline & Transf. Municípios & & $(4,997)$ & 1,779 & 3,266 & 766 & 1,728 & $(3,890)$ \\
\hline & União & & $(2,433)$ & 845 & 1,604 & 356 & 807 & $(1,819)$ \\
\hline & Estados & & $(2,565)$ & 933 & 1,662 & 410 & 921 & $(2,071)$ \\
\hline & Transf. União-Estados & & $(2,192)$ & 766 & 1,451 & 322 & 728 & $(1,646)$ \\
\hline
\end{tabular}

Nota: ${ }^{*}$ ) Receita da parcela principal dos tributos, exclusive dívida ativa e multas e juros.

Fonte: Elaboração própria.

Tabela A.2 - Estimativa do componente cíclico das transferências, 2009-2014 (em R\$ milhões)

\begin{tabular}{|c|c|c|c|c|c|c|c|c|}
\hline \multirow{13}{*}{$\begin{array}{l}\text { Repetição } \\
\text { de receitas }\end{array}$} & Discriminação & Vinculação & 2009 & 2010 & 2011 & 2012 & 2013 & 2014 \\
\hline & FPM (IR+IPI) & 19,0 & $(1,847)$ & 638 & 1,214 & 268 & 610 & $(1,371)$ \\
\hline & FPE (IR+IPI) & 17,2 & $(1,672)$ & 578 & 1,099 & 246 & 552 & $(1,241)$ \\
\hline & IPI Exp-Mun & 2,0 & $(31)$ & 13 & 23 & 5 & 11 & $(26)$ \\
\hline & IPI Exp-Est & 6,0 & (93) & 39 & 69 & 16 & 32 & (79) \\
\hline & FUNDEB-Mun (FPM-FPE) & 5,0 & $(488)$ & 169 & 320 & 71 & 161 & $(362)$ \\
\hline & FUNDEB-Est (FPM-FPE) & 3,8 & $(368)$ & 127 & 242 & 53 & 212 & $(273)$ \\
\hline & FUNDEB-Mun (IPI Exp) & 1,1 & (18) & 7 & 13 & 3 & 6 & (15) \\
\hline & FUNDEB-Est (IPI Exp) & 0,9 & (13) & 6 & 10 & 2 & 5 & (11) \\
\hline & SalEdu-Mun & 31,2 & $(49)$ & 18 & 34 & 9 & 19 & (45) \\
\hline & SalEdu-Est & 28,8 & $(45)$ & 16 & 31 & 8 & 18 & $(42)$ \\
\hline & Cota ICMS (c/ FUNDEB) & 31,4 & $(2,565)$ & 933 & 1,662 & 410 & 921 & $(2,071)$ \\
\hline & PIB tendencial/PIB efetivo & & 1,0275 & 0,9914 & 0,9862 & 0,9969 & 0,9937 & 1,0133 \\
\hline
\end{tabular}

Fonte: Elaboração própria. 
Gráfico A.1 - FiltroHodrick-Prescott (HP): PIB e tendência, 1996-2014 (1995 = 100)

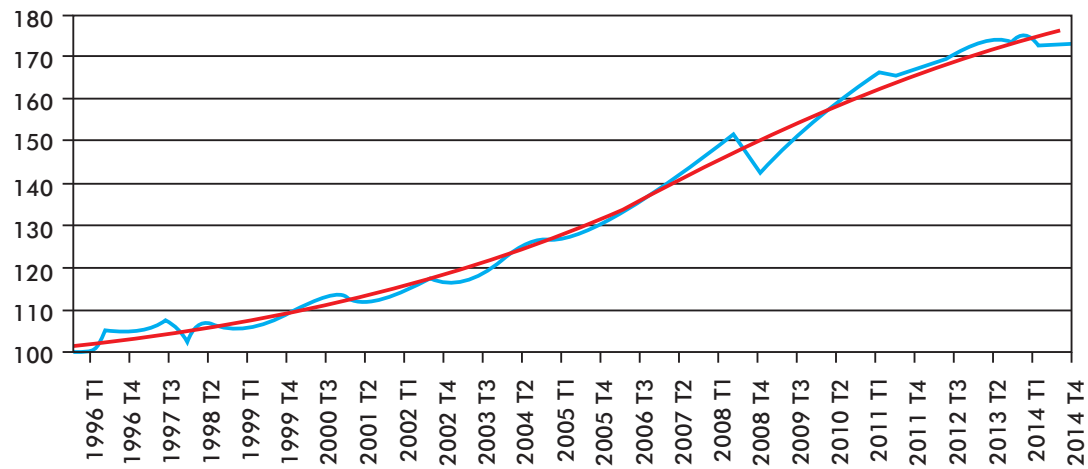

PIB

Tendência

Fonte: Elaboração própria. 